\title{
Improvement of the corrosion behavior of AISI 304L stainless steel by deep rolling treatment under cryogenic cooling
}

\section{Khouloud Gharbi}

Laboratoire de Mécanique, Matériaux et Procédés (LR99ES05), ENSIT, Université de Tunis, Naoufel Ben Moussa

Laboratoire de Mécanique, Matériaux et Procédés (LR99ES05), ENSIT, Université de Tunis,

\section{Amir Ben Rhouma}

Laboratoire de Mécanique, Matériaux et Procédés (LR99ES05), ENSIT, Université de Tunis,

Nabil Ben Fredj ( $\square$ nabil.benfredj@esstt.rnu.tn )

Laboratoire de Mécanique, Matériaux et Procédés (LR99ES05), ENSIT, Université de Tunis, https://orcid.org/0000-0001-6720-2377

\section{Research Article}

Keywords: Deep rolling, Cryogenic cooling, AISI 304L stainless steel, Rolling speed, Corrosion behavior.

Posted Date: March 30th, 2021

DOl: https://doi.org/10.21203/rs.3.rs-329725/v1

License: (c) (i) This work is licensed under a Creative Commons Attribution 4.0 International License. Read Full License 


\title{
Improvement of the corrosion behavior of AISI 304L stainless steel by deep rolling treatment under cryogenic cooling
}

\author{
Khouloud Gharbi*, Naoufel Ben Moussa*, Amir Ben Rhouma*, Nabil Ben Fredj* \\ * : Laboratoire de Mécanique, Matériaux et Procédés (LR99ES05), ENSIT, Université de \\ Tunis, 5 Av. Taha Hussein Montfleury, 1008 Tunis, Tunisia.
}

e-mail address of the first author: Gharbi khouloud90@hotmail.fr

e-mail address of the second author: emailnaoufel@gmail.com

e-mail address of the third author: amir.benrhouma@ensit.rnu.tn

e-mail address of the fifth author: benfredjnabil@gmail.com

e-mail address of the corresponding author: benfredjnabil@gmail.com 


\begin{abstract}
The effects of deep rolling parameters; particularly, work speed and cooling conditions (dry and cryogenic) on the surface integrity of AISI 304L machined samples and their further impact on uniform and localized corrosion behavior in chloride environment were experimentally investigated in this work. The electrochemical behavior of machined and deep rolled samples was assessed using cyclic potentiodynamic polarization tests in synthetic seawater. Findings of this study exhibit that grain refinement generated in the surface layers leads to improved corrosion behavior of deep rolled specimens with regard to machining state. In addition, machined samples deep rolled at a speed of $25 \mathrm{~m} / \mathrm{min}$, without cooling, showed better corrosion resistance than those processed under cryogenic cooling. However, the application of cryogenic deep rolling at speeds of $75 \mathrm{~m} / \mathrm{min}$ and $120 \mathrm{~m} / \mathrm{min}$ significantly enhanced the electrochemical behavior of mechanically treated specimens. It was found that the corrosion behavior of AISI 304L deep rolled components is related to combined factors (surface roughness, strain-induced martensite, microhardness, residual stress). Despite of high amounts of strain-induced martensite that can deteriorate the electrochemical behavior, it was shown that deep rolled specimens under cryogenic cooling with low surface roughness depict better uniform and localized corrosion resistances.
\end{abstract}

Key words: Deep rolling, Cryogenic cooling, AISI 304L stainless steel, Rolling speed, Corrosion behavior. 


\section{Introduction}

Stainless steels have been extensively used in several industrial fields such as power plants, shipping, desalination plants, gas production and offshore oil, etc. due to their excellent corrosion resistance in aggressive environments. Particularly, austenitic stainless steels have been widely applied in chemical industries owing to the formation of surface protective passive film [1]. Their chromium content varies from 16 to $28 \%$ and nickel content varies from 3.5 to $32 \%$ [2]. Actually, chromium protects the metal substrate from uniform and localized corrosion e.g., pitting, crevice, stress corrosion cracking and intergranular corrosion by the creation of insoluble film of protection [3]. Nevertheless, passive films are mainly susceptible to rupture in the presence of chloride anions in seawater resulting in pitting corrosion [4]. Among the types of austenitic stainless steels, 304L is an extensively employed grade in several industries like petrochemical, food, aerospace etc. Despite its good corrosion resistance owing to the chromium-based passivation film and the film stabilizing action of nickel [5], it is highly sensitive to local corrosion in chloride environments. It is known that environmental conditions, as well as interrelated geometrical, metallurgical factors and surface conditions resulting from manufacturing processes strongly affect the corrosion behavior of stainless steels [6]. Hence, limited mechanical surface treatments such as thermo-mechanical treatment [3], shot and ultrasonic peening [7], nano peening [8] and laser shock processing $[9,10]$ have been used to enhance the electrochemical behavior of austenitic stainless steels. It should be noted that surface modifications (microstructure, grain size, surface roughness, microhardness, residual stress, etc.) generated by these mechanical processes are considered as the key factors for modifying the corrosion behavior of AISI 304/304L components. Toppo et al. [3] studied the effects of a thermo-mechanical surface treatment, including conventional shot blasting with subsequent laser surface heating, on the electrochemical behavior of the AISI 304 stainless steel. It has been reported that this surface treatment lead to recrystallized fine grains and straininduced martensite in the affected layer. Authors noted that grain refinement, the dispersion and redistribution of alumina inclusions are the main factors controlling the corrosion resistance of thermo-mechanically treated AISI 304. Lee et al [7] pointed out that shot and ultrasonic peening of AISI 304 produce nano-sized grains of $20-30 \mathrm{~nm}$ on the surface layer resulting in the increase of surface microhardness by about 50-100 HV comparatively to untreated surface. In addition, authors found that ultrasonically peened sample with lower surface roughness and higher volume fraction of plastic-induced martensite (48\%) exhibits better general and localized corrosion resistance than the shot peened sample. Saada et al. [8] mentioned that severe shot 
peening of AISI 304L induces a nanocrystallized surface layer of $150 \mu \mathrm{m}$ thickness that consists of ferrite grains enriched with $\mathrm{Cr}$ and Mo contents. Thus, the improvement of the corrosion resistance is attributed to the $\mathrm{Cr}$ diffusion on the protective film. Besides, the mechanical wear resistance is enhanced by the surface work hardening after nano peening. Lu et al. [9] showed that the corrosion behavior improvement of AISI 304 after the application of massive laser shock peening (LSP) is attributed to refined surface layer and deep compressive residual stress distribution that reaches a depth of around $900 \mu \mathrm{m}$. Nevertheless, surface modifications induced by some mechanical treatments can deteriorate the corrosion resistance of materials subjected to corrosive environments, depending on process parameters. Pałka et al. [11] reported that increasing burnishing load up to $3000 \mathrm{~N}$ reduces the surface roughness by over $80 \%$ and increases the yield stress from $230 \mathrm{MPa}$ to $450 \mathrm{MPa}$, whereas the AISI 304 electrochemical behavior in citric acid solution decreases accordingly. Other studies [12,13] mentioned that plasma nitriding at temperatures ranging between $230^{\circ} \mathrm{C}$ and $450^{\circ} \mathrm{C}$ leads to the formation of S-phase that significantly enhances the corrosion properties of austenitic stainless steels. However, it has been reported that the presence of $27 \%$ volume fraction of martensite in the austenite matrix deteriorates the corrosion resistance of AISI 304L nitrided at temperature above $460^{\circ} \mathrm{C}$. Wei et al. [10] pointed out that single LSP (Laser Shock Peening) produces refined grains in the surface layers, compressive residual stress of about $-235 \mathrm{MPa}$ and $24 \%$ volume fraction of martensite. It has been stated that the combined effect of grain refinement and compressive residual stress significantly improves the corrosion behavior of the AISI 304 stainless steel in acid chloride solution. However, it was found that double LSP increases the surface hardness from $225 \mathrm{HV}$ to $322 \mathrm{HV}$ and generates a volume fraction of strain-induced martensite of $32 \%$ that decreases the corrosion resistance of treated samples. Consequently, it can be stated from the above literature that it is important to understand the overall effect of surface modifications (surface roughness, grain size, microstructure, residual stress, etc.) resulting from the processing of the austenitic stainless steels to explain their corrosion behavior.

In recent years, many investigations have been focused on studying the effects of the environment under which the mechanical surface treatments are applied. Attention was given to the application of coolant to reduce the harmful thermal effects that may occur during these treatments. For example, cryogenic cooling has been used in roller burnishing [14-16] to enhance materials characteristics. Pu et al. [14] studied the effect of cryogenic burnishing on the corrosion improvement of $\mathrm{AZ31B} \mathrm{Mg}$ alloy in $\mathrm{NaCl}$ solution. The reported improvements are attributed to the reduction of grain size and basal-textured grain orientation. Yang et al. [15] 
reported that cryogenic burnishing significantly improves the surface integrity of Co-Cr-Mo alloy due to refined grains, increased hardness and strain-induced phase transformation on the surface layer. Caudill et al. [16] showed that cryogenic burnishing drastically enhances Ti-6Al$4 \mathrm{~V}$ alloy properties in comparison with dry and flood-cooled burnishing. The authors concluded that cryogenic cooling controls the detrimental effect of thermal softening. As surface modifications are the critical factors for enhanced in-service life of AISI 304L stainless steel subjected to hard conditions (corrosive environment, fatigue, wear, etc.), studies are carried out to enhance the surface integrity by means of innovative mechanical surface treatments. Within this framework, deep rolling (DR) treatment has proven its effectiveness to enhance the surface characteristics, i.e. surface smoothing, introduction of compressive residual stresses and surface strengthening. In addition, this surface treatment is increasingly used to improve the fatigue behavior of austenitic stainless steels [17-19]. Nevertheless, the application of deep rolling under cryogenic cooling to improve the corrosion behavior of AISI 304L components in chloride environments has not been studied, yet.

The current study aims at evaluating the surface integrity of AISI 304L machined surfaces and finished using the deep rolling process under dry and cryogenic conditions. It focuses on the potentialities of this mechanical surface treatment and the cooling mode to enhance the resistance to uniform and localized corrosion in synthetic seawater environment. Moreover, limits of the corrosion resistance improvement and its dependency on the process conditions are investigated. For this purpose, experiments were performed to assess the effects of deep rolling parameters; namely, work speed and cooling method on the resulting surface integrity that is evaluated by means of surface topography, microstructure, surface work hardening and residual stress distributions. Moreover, the corrosion properties of machined and deep rolled AISI 304L workpieces was determined by electrochemical tests.

\section{Material and testing methods}

\subsection{Work material}

The material used in this investigation was the AISI 304L austenitic stainless steel supplied as solution annealed (RS) bars. The chemical composition and mechanical properties at $20^{\circ} \mathrm{C}$ are listed in Tables 1 and 2, respectively. The as-received Vickers hardness of the tested material is around $197 \mathrm{HV}_{0.1}$ and its microstructure is shown in Figure 1. The average grain size of the work material is around $50 \mu \mathrm{m}$. 
Table 1 Chemical composition (wt. \%) of the tested AISI 304L stainless steel

Table 2 Mechanical properties of the tested AISI 304L stainless steel at $20^{\circ} \mathrm{C}$

Fig. 1 Microstructure of the tested AISI 304L stainless steel

\subsection{Experimental set-up}

\subsubsection{Machining}

Specimens of $30 \mathrm{~mm}$ diameter and $20 \mathrm{~mm}$ thickness (Figure 2) were machined by turning under lubricated conditions using soluble oil (5\%). The selection of the cutting conditions were based on SANDVIK recommendations for stainless steels. A VBMT 1604 04-MF 2015 coated carbide insert was used to reduce the diameter from 30 to $29.5 \mathrm{~mm}$ at a feed rate of 0.4 $\mathrm{mm} / \mathrm{rev}$ and a cutting speed of $100 \mathrm{~m} / \mathrm{min}$ in order to standardize initial deep rolling conditions. A rake angle $\gamma$ of $0^{\circ}$, a clearance angle $\alpha$ of $5^{\circ}$ and a nose radius $\mathrm{R}_{\varepsilon}$ of $1.2 \mathrm{~mm}$ characterize the insert geometry.

Fig. 2 Workpiece geometry (mm)

\subsubsection{Deep rolling tool}

In this study, a deep rolling tool with an interchangeable roller was designed and manufactured to achieve high processing forces. A schematic representation of the deep rolling tool is illustrated in Figure 3. The tool consists of two hardened steel parts in which the foremost part is a mandrel (7) of hardened steel that holds a roller (9), while the supplementary part (6) of square cross section is a firmly clamped shank on the lathe's tool post. The roller holder (7) can accommodate a heat-treated roller with a contact width of $4 \mathrm{~mm}$. The roller (9) can be easily removed from (7) for changing or cleaning by unscrewing the pin (8). A ball bearing (10) was used to reduce rotational friction when the roller is pushed against the samples. Needle roller thrust bearings (12) were used to sustain high axial loads and to prevent peak loads when 
operating. The AISI D2 roller was subjected firstly to an austenitization at $1050^{\circ} \mathrm{C}$ (vacuum atmosphere) for $15 \mathrm{~min}$ followed by air-cooling and secondly to a double tempering at $550^{\circ} \mathrm{C}$ for $2 \mathrm{~h}$ each time followed by cooling with brewed nitride at temperature $\mathrm{T}=24^{\circ} \mathrm{C}$ and pressure $\mathrm{P}=5$ bar. The measured average hardness and surface roughness (Ra) of the roller, after polishing, were about $62 \mathrm{HRc}$ and $0.01 \mu \mathrm{m}$, respectively.

Fig. 3 Details of the deep rolling tool

\subsubsection{Procedure of deep rolling}

The deep rolling experiments were applied on a turning machine equipped with a liquid nitrogen delivery system as shown in Figure 4. The deep rolling process was performed directly after turning operation without removing the workpiece from the lathe chuck in order to maintain the same turning alignment and to avoid roundness error. For dry conditions, no cooling was used; while for cryogenic conditions, liquid nitrogen was delivered to the toolworkpiece interface. The nitrogen was applied through a nozzle with a circular section of 50 $\mathrm{mm}^{2}$ under a pressure of 0.3 MPa. The roller was free to rotate when contacting the workpiece due to the frictional forces developed at the interface between the roller and the workpiece.

Even though previous studies have identified six parameters controlling the deep rolling process (depth of penetration DoP, speed $\mathrm{V}$, feed rate $\mathrm{f}$, number of passes $\mathrm{N}_{\mathrm{r}}$ and cooling method), only speed and cooling mode were considered in this investigation. The speed range was established based on the work of Nikitin et al. [17] and Ben Moussa et al. [19]. The depth of penetration and feed were set to $0.08 \mathrm{~mm}$ and $0.05 \mathrm{~mm} / \mathrm{rev}$, respectively. These values were selected according to the studies conducted by Yang et al. [15] and Candill et al. [16]. The experimental conditions are summarized in Table 3.

In the current study, the range of speed was varied to evaluate possible correlations of deep rolling parameters, cooling conditions and surface integrity in order to establish combinations of experimental conditions to improve the corrosion behavior of machined AISI 304L components. 
Fig. 4 Deep rolling set-up ( $\mathrm{F}_{\mathrm{r}}$ and $\mathrm{F}_{\mathrm{a}}$ are radial and axial DR forces)

Table 3 Deep rolling experimental conditions

\subsection{Testing methods}

The deep rolling force components were measured using a piezoelectric transducer basedtype dynamometer (Kistler 9257B). A RayCam CA1886 infrared thermo-camera was used during the experiments to record the whole thermal field. The surface roughness was evaluated using a MITUTOYO Surftest type SJ 301. Scanning Electron Microscope (SEM) examinations of machined and deep rolled surfaces were performed using Carl Zeiss SUPRA 5 VP. The surface hardening was characterized by microhardness measurements using a Wolpert Wilson Micro Vickers hardness tester 402 MVD device under a load of 100 gf. Three measurements were performed at each depth, and then averaged to take into consideration the measurement errors. Samples were cut from the machined and deep rolled workpieces for metallurgical examinations. Oxalic acid solution was used as an etchant to reveal the grain structure after polishing using emery papers (Grades 1000, 1600 and 2400). Optical microscope was used to reveal the machined and deep rolled microstructures. Phase analysis was conducted using a Philips PANalytical X-ray diffractometer with $\mathrm{Cu}-\mathrm{K} \alpha$ radiation $\left(\lambda=1.54184 \AA, \mathrm{K}_{\alpha 1} / \mathrm{K}_{\alpha 2}=0.5\right)$ from a source operated at $45 \mathrm{kV}$ and $40 \mathrm{~mA}$. The X-ray diffractometry was used to evaluate the quantitative measurement of the strain-induced martensite by evaluating the integrated intensity of each peak. The volume fraction of $\alpha^{\prime}$-martensite $\left(V_{\alpha^{\prime}}\right)$ on the surface layer is calculated using the following equation [7]:

$$
V_{\alpha^{\prime}}=\frac{\frac{1}{n} \sum_{j=1}^{n} \frac{I_{\alpha^{\prime}}^{j}}{R_{\alpha^{\prime}}^{j}}}{\frac{1}{n} \sum_{j=1}^{n} \frac{I_{\gamma}^{j}}{R_{\gamma}^{j}}+\frac{1}{n} \sum_{j=1}^{n} \frac{I_{\alpha^{\prime}}^{j}}{R_{\alpha^{\prime}}^{j}}}
$$


where $n, I$ and $R$ represent the number of peaks corresponding to each phase, the integrated intensity of the reflecting plane and the material scattering factor, respectively. The residual stress profiles were determined using a GNR X-ray diffractometer under the conditions reported in Table 4. For in-depth measurements, metal removal was carried out by the electrochemical etching technique.

The electrochemical reactivity of deep rolled specimens in artificial seawater was evaluated by cyclic polarization tests conducted using a PGZ301 Voltalab 40 potentiostat at ambient conditions $\left(\mathrm{T}=25^{\circ} \mathrm{C} \pm 1\right)$ with a potential scan rate of $2.5 \mathrm{mV} / \mathrm{s}$. In the standard 3-electrode corrosion cell, a Saturated Calomel Electrode (SCE) was used as a reference electrode and a platinum (Pt) gauze as a counter electrode. The deep rolled samples were covered with an Otype resin ring (test area $10 \mathrm{~mm}^{2}$ ), then immersed in the synthetic seawater solution $(20 \mathrm{ml})$. The synthetic seawater was prepared in the laboratory according to ASTM D 1141-81 standard and its $\mathrm{pH}$ was adjusted to $8.2 \mathrm{using} 0.1 \mathrm{~mol} . \mathrm{L}^{-1} \mathrm{NaOH}$ solution. 


\section{Results}

The surface integrity of the AISI 304L deep rolled samples under the experimental conditions listed in Table 3 are evaluated in terms of surface roughness, microstructure, microhardness and residual stresses. Indeed, the literature review presented in section 1 indicated that these are the main parameters of the surface integrity that control the corrosion behavior of metallic components. It is important to notice that, in this work, attention is accorded particularly to the effects of the cryogenic cooling on the deep rolling process and to the resulting surface integrity and corrosion behavior.

\subsection{Effect of the cryogenic cooling on the deep rolling process}

\subsubsection{Deep rolling forces}

Relationships between the radial and axial deep rolling force components, $F_{r}$ and $F_{a}$, at different work speed (V) for the investigated cooling modes are shown in Figure 5(a) and (b) respectively. It can be seen that deep rolling under cryogenic cooling generates higher radial and tangential force components when compared to those generated under dry deep rolling condition. Moreover, it is observed that the highest levels of deep rolling force components are obtained when processing under conditions with low speed. For the more, it can be stated that radial force differences between dry and cryogenic conditions become low at the highest speed level $(120 \mathrm{~m} / \mathrm{min})$.

Fig. 5 Effect of the cooling mode on (a) the DR radial force and (b) the DR axial force

\subsubsection{Deep rolling temperature}

The temperature map during deep rolling process under cryogenic cooling is shown in Figure 6 that depicts the process-induced temperature variations along the axial direction of the workpiece. Cryogenic cooling by liquid nitrogen significantly reduces the deep rolling temperature at the roller-workpiece contact point (Figure 7). In addition, it is observed that the highest temperature level is recorded at the contact zone between the roller and the workpiece 
and decreased smoothly with increasing distance toward the end of the sample. It is also remarked that the maximum temperature value at the contact region is reached when processing with a high work speed. According to Manimaran et al. [20], liquid nitrogen sprayed on the interface between the deep rolling tool and the workpiece forms a gas/fluid cushion that effectively reduce the friction force in the contact point and provides an efficient absorption of heat. The temperature reduction is considered as the major reason for the favorable effects of cryogenic cooling.

Fig. 6 Effect of cryogenic cooling mode and work speed on the deep rolling temperature

Fig. 7 Effect of the cooling mode on the deep rolling temperature at the roller-workpiece contact point

\subsection{Effect of the cryogenic cooling on the AISI 304L deep rolled surface integrity}

\subsubsection{Surface topography}

SEM micrographs of AISI 304L machined surfaces depict machining grooves (Figure 8a) that are completely removed after deep rolling under cryogenic cooling (Figures 8c). This can be explained by the repetitive action of the roller on the workpiece resulting in the increase of surface homogeneity and thus better surface finish is generated. Since the AISI 304L Stainless Steel has a low thermal conductivity, the frictional forces increase during deep rolling process, and so the temperature increases at the contact zone (Figure 7). In the case of dry condition, surface asperities generated by the machining process are quite difficult to be completely removed when processing by deep rolling (Figure $8 \mathrm{~b}$ ). However, the liquid nitrogen applied to the deep rolling zone highly reduces the softening of the studied material, and so the surface asperities can be readily eliminated (Figure 8c).

The micro-geometrical quality of the deep rolled surface is characterized by the arithmetic $\left(\mathrm{R}_{\mathrm{a}}\right)$ and the total $\left(\mathrm{R}_{\mathrm{t}}\right)$ roughness parameters (Column A of table 5). The $\mathrm{R}_{\mathrm{a}}$ and $\mathrm{R}_{\mathrm{t}}$ of each 
sample is the average values of three measurements. It can be seen that the application of deep rolling significantly improves the surface micro geometrical quality of AISI 304L machined surfaces. Indeed, the mean roughness $\mathrm{R}_{\mathrm{a}}$ is reduced from 4.04 to $1.03 \mu \mathrm{m}$ and the total roughness $\mathrm{R}_{\mathrm{t}}$ decreased from 18.53 to $5.34 \mu \mathrm{m}$ when processing under dry condition at a speed of 25 $\mathrm{m} / \mathrm{min}$. Figures 9(a) and (b) show that the application of liquid nitrogen when processing leads to a considerable improvement of surface roughness comparatively to dry condition. The maximum decreases of surface roughness parameters, under the application of liquid nitrogen, are obtained at a work speed of $120 \mathrm{~m} / \mathrm{min}$. Under these conditions, the mean roughness $\mathrm{R}_{\mathrm{a}}$ is reduced by $92 \%$ and the total roughness $\mathrm{R}_{\mathrm{t}}$ is decreased by $89 \%$ comparatively to machined state.

(a)

(b)

(c)

Fig. 8 SEM observations of machined and deep rolled specimens a) machined b) deep rolled under dry condition at $120 \mathrm{~m} / \mathrm{min} \mathrm{c}$ ) deep rolled under cryogenic conditions at $120 \mathrm{~m} / \mathrm{min}$ 
(a) Mean surface roughness $\mathrm{R}_{\mathrm{a}}$

(b) Total surface roughness $\mathrm{R}_{\mathrm{t}}$

(c)

Figure 9 Effects of the cooling mode on the surface roughness of deep rolled surfaces of the AISI 304L Stainless Steel

\subsubsection{Microstructure}

Optical micrograph of the turned AISI 304L cross-section (Figure 10) reveals a deformed structure characterized by slip lines localized at the stretched grains [21]. The bulk material microstructure is close to the as-received state that consists in equiaxed grains with an average size ranging from 30 to $50 \mu \mathrm{m}$. However, metallographic examinations of the cross section of deep rolled samples (Figure 11) depict a clear interface between a re-crystallized layer with indistinct grain boundaries formed at the topmost surface and a subsequent transition layer characterized by the pattern of sweeping grains. In fact, a large amount of intersecting and irregular multiple-slip bands marked by a high density of deformation twins is observed near the topmost surface as shown in Figure 11. With an increasing depth into the matrix, single slips progressively substitute multiple-slip bands located in the near-surface regions. It can be stated that the deep rolled surface microstructures consist in austenite grains $\gamma$, which have partially transformed to $\alpha^{\prime}$-martensite grains due to severe plastic deformation. The $\gamma \rightarrow \alpha^{\prime}$ transformation is attributed to the nucleation of $\alpha^{\prime}$-martensite at the intersecting twins due to the relatively low intrinsic stacking fault energy of austenitic stainless steels [22]. Many investigations [3, 7] reported similar results for stainless steels type 304.

The topmost deep rolled surface layers consist in ultra-refined grains which are not clearly visible (Figure 11). These results highlights the fact that the successive action of the deep rolling tool results in severe plastic deformation (SPD) that further leads to grain refinement [23, 24]. Indeed, the deep rolling process generates high-energy impacts at high deformation rates, which consequently creates dislocations. Therefore, the number of dislocations progressively increases due to the repetitive impacts. Moreover, it was observed that the thickness of refined layers becomes smaller at higher deep rolling speeds (Figures 11c and 11d) as the refined grains in the subsurface will grow larger [25]. 
Fig. 10 Cross section micrograph of the machined AISI 304L sample

(a)

(b)

(c)

(d)

Fig. 11 Cross section micrographs of deep rolled AISI 304L samples : (a) dry at $25 \mathrm{~m} / \mathrm{min}$, (b) Cryogenic at $25 \mathrm{~m} / \mathrm{min}$, (c) dry at $120 \mathrm{~m} / \mathrm{min}$ and (d) cryogenic at $120 \mathrm{~m} / \mathrm{min}$

\subsubsection{Phase changes}

Figure 12 shows X-ray diffraction patterns of the machined and deep rolled samples. It is known that the austenite phase in type 304L stainless steel is unstable when deformed at room temperature and tends to transform into strain-induced martensite $\alpha^{\prime}$ [26]. The XRD spectra of the machined specimen consists of $\gamma$-austenite peaks, while both $\gamma$-austenite and $\alpha^{\prime}$-martensite peaks are observed in the case of deep rolled surfaces. Actually, $\alpha^{\prime}$ peaks exhibit the existence of remnant martensite (formed during deep rolling process) which has failed to transform completely into austenite along with the increased intensity of the austenite peak resulting from surface recrystallization. During the deep rolling treatment, $\alpha^{\prime}$-martensite induced in the plastically deformed layers tends to transform back into austenite, whereas the complete transformation $\gamma \rightarrow \alpha^{\prime}$ is not achieved due to the short interaction time of the deep rolling treatment [27]. Besides, the martensitic transformation occurs with the formation of intersecting twins resulting from the successive stacking fault overlap on (111) $\gamma$ plane during plastic deformation [7].

Considering the existence of mainly two phases in the processed samples, the (111), (200), (220), (311) and (222) reflection planes for $\gamma$-austenite as well as (110), (200), (211) and (220) reflection planes for $\alpha^{\prime}$-martensite are used to estimate the volume fraction of each phase by means of Eq. 1. The calculated volume fractions of the strain-induced martensite in the machined and deep rolled workpieces are reported in column $\mathrm{C}$ of Table 5.

It clearly appears that deep rolling under cryogenic cooling produces higher amount of plasticinduced martensite than that generated at the dry condition. This result agrees with the study of Tourki et al. [26] reporting that high deformation rates and low temperatures promote the 
formation of $\alpha^{\prime}$-martensite. According to figure 12, the highest volume fractions of straininduced martensite obtained after deep rolling at a work speed of $25 \mathrm{~m} / \mathrm{min}$ under dry condition and cryogenic cooling are $40 \%$ and $21 \%$, respectively. However, no significant difference is found between the volume fractions of $\alpha^{\prime}$-martensite generated after deep rolling at $75 \mathrm{~m} / \mathrm{min}$ and at $120 \mathrm{~m} / \mathrm{min}$ under dry and cryogenic conditions.

Fig. 12 XRD spectra of machined and deep rolled AISI 304L surfaces with the volume fractions of strain-induced martensite

\subsubsection{Surface work hardening}

Surface work hardening induced by machining and deep rolling process was performed as described in section 2.3. Measurements results are shown in column B of Table 5 and Figure 13. This figure clearly reveals the existence of work-hardened layers induced by plastic deformation under both conditions; dry and cryogenic cooling. The surface hardening rate is increased by $94 \%$ for the turned surfaces with regard to the bulk material (197 $\left.\mathrm{HV}_{0.1}\right)$. It can be seen that the highest surface hardness values are recorded when processing at a deep rolling speed of $25 \mathrm{~m} / \mathrm{min}$. At this speed, the hardening increasing rate is about $127 \%$ for deep rolled surfaces under dry condition comparatively with the turned state. Moreover, cryogenic cooling is seen to introduce higher surface work hardening where the average increase of the surface hardness is $142 \%$. These results are in a good agreement with the deep rolling forces generated at this speed. Concerning depths of the hardened layers, profiles of Figure 13 show that the turning process generated a work-hardened layer of about $400 \mu \mathrm{m}$. Meanwhile, depths of these layers are about $650 \mu \mathrm{m}$ and $800 \mu \mathrm{m}$ for deep rolled surfaces under dry and cryogenic cooling, respectively. For the deep rolling speeds of $75 \mathrm{~m} / \mathrm{min}$ and $120 \mathrm{~m} / \mathrm{min}$, no significant differences of hardening at the under layers was highlighted (Figure 13). The increased AISI 304L surface hardness results from ultra-fined grains generated in the near-surface regions [15] and plasticinduced martensite (Column C of Table 5) [22]. 
(a)

(b)

(c)

Fig. 13 Microhardness profiles of the AISI 304L samples deep rolled at (a) $25 \mathrm{~m} / \mathrm{min}$, (b) $75 \mathrm{~m} / \mathrm{min}$ and (c) $120 \mathrm{~m} / \mathrm{min}$

\subsubsection{Residual stress}

The surface residual stress measurements in the longitudinal $\left(\sigma_{11}\right)$ and the transverse $\left(\sigma_{22}\right)$ directions for machined and deep rolled samples are shown in Column D of Table 5. It is observed that machining process generates tensile residual stress distribution in the transverse direction (360 MPa), whereas the axial residual stress fields are compressive (-394 MPa). These stresses are generated by the thermal and mechanical effects that take place at the material-tool interfaces during the material removal by turning process [28].

The near-surface residual stress profiles of AISI 304L deep rolled samples under both dry and cryogenic conditions are shown in Figure 14. It should be noted that XRD measurements were limited to a depth around $800 \mu \mathrm{m}$. Beyond this depth, the measured residual stress levels are considered unreliable because of the coarse grain size [29]. It can be seen that compressive residual stress distributions in both directions are obtained after the application of deep rolling under dry and cryogenic conditions. The compressive residual stresses resulting from the mechanical effects of deep rolling forces (Figure 4) are formed in order to create an equilibrium state between the surface and the near-surface layers [30]. The surface residual stress levels in the longitudinal direction are much higher than in the transverse direction. Moreover, the application of liquid nitrogen increases significantly the compressive residual stress amplitudes in both conditions. Here, the maximum recorded increase is about $319 \mathrm{MPa}$ for $\sigma_{11}$ and 109 MPa for $\sigma_{22}$ which is observed after deep rolling at a work speed of $75 \mathrm{~m} / \mathrm{min}$ with regard to dry condition (Column D of Table 5). Analysis of the residual stress profiles of the deep rolled surfaces under both dry and cryogenic conditions reveals that the highest levels of the compressive stresses are reached at depths ranging from $50 \mu \mathrm{m}$ to $100 \mu \mathrm{m}$ (Figure 14). Under cryogenic cooling, the maximum levels measured for each work speed rate are $\sigma_{11}=-1221$ $\mathrm{MPa}$ and $\sigma_{22}=-765 \mathrm{MPa}$ for $V=25 \mathrm{~m} / \mathrm{min} ; \sigma_{11}=-1155 \mathrm{MPa}$ and $\sigma_{22}=-728 \mathrm{MPa}$ for $V=75$ $\mathrm{m} / \mathrm{min}$ and $\sigma_{11}=-1173 \mathrm{MPa}$ and $\sigma_{22}=-710 \mathrm{MPa}$ for $V=120 \mathrm{~m} / \mathrm{min}$. 
Accordingly, the highest levels of the compressive residual stresses are obtained when processing at a work speed of $25 \mathrm{~m} / \mathrm{min}$ using cryogenic cooling for which a content of $40 \%$ of strain-induced martensite was evaluated. This result is in good agreement with the findings of Wojciech et al. [31] that reported that the martensitic transformation from metastable austenite leads to volume increase that makes the stresses in the martensite highly compressive. The measured surface residual stress values are found to be correlated with the corresponding straininduced martensite volume fractions (Columns C and D of Table 5).

(a)

(b)

Fig. 14 Effect of deep rolling on the residual stress profiles in (a) the longitudinal direction $\sigma_{11}$ and (b) the transverse direction $\sigma_{22}$

Table 5 Results of surface characterization of AISI 304L machined and deep rolled samples.

\subsection{Effect of the cryogenic cooling on the AISI 304L deep rolled corrosion behavior}

Corrosion behavior of machined and deep rolled samples is assessed by means of potentiodynamic anodic polarization test in synthetic seawater. The corrosion current density (Icorr) and the corrosion potential (Ecorr) are determined from polarization curves shown in Figure 15. The pit potential (Epp), passivation potential (Epass) and passivation current density (Ipass) are evaluated from cyclic polarization curves given by Figure 16. Results are reported in Table 6. The Icorr and Ecorr values are calculated using Tafel extrapolation method. It can be clearly seen from Table 6 that the application of deep rolling after machining generates lower values of Icorr and Ecorr. Ennobled potentials Epp and Epass and likewise, lower values of Ipass are obtained. It is known that low values of Icorr and ennobled values of Ecorr depict higher resistance to uniform corrosion [3, 7]. Similarly, Epp and Epass with more positive values indicate better resistance to pitting corrosion [32]. Besides, low values of Ipass indicate higher stability of the formed passive film [3]. Therefore, these results point out the fact that deep rolling process improves the resistance to uniform and to pitting corrosion of machined 
surfaces. Concerning the effect of the deep rolling environment, no general conclusion can be given. Indeed, Table 6 indicates that the application of the cryogenic cooling generates higher corrosion resistance for high working speeds only $(75 \mathrm{~m} / \mathrm{min}$ and $120 \mathrm{~m} / \mathrm{min})$. For low working speed $\mathrm{V}=25 \mathrm{~m} / \mathrm{min}$, deep rolling the AISI 304L under dry condition offers better corrosion resistance. Nevertheless, it can be established that enhanced resistance to uniform and to pitting corrosion and better stability of passive film can be achieved when deep rolling treatment is performed at high-speed rates under cryogenic cooling. As shown in Table 6, for the working speed of $120 \mathrm{~m} / \mathrm{min}$, the corrosion potential Ecorr shifts from -201 mV/SCE for dry condition to $338 \mathrm{mV} / \mathrm{SCE}$ when liquid nitrogen is applied and an increase of the pit potential (Epp) of about $18 \%$ was recorded in this case.

Fig. 15 Potentiodynamic polarization curves of machined and deep rolled samples in synthetic seawater

Fig. 16 Cyclic potentiodynamic polarization curves of machined and deep rolled samples in synthetic seawater

Table 6 Results of potentiodynamic polarization tests of AISI 304L machined and deep rolled samples in synthetic seawater

In order to explain these enhancements of the corrosion resistance of AISI 304L machined surfaces, it is essential to investigate the effects of surface integrity modifications resulting from the deep rolling process on the resistance to uniform and to pitting corrosion in aggressive environments.

\section{Discussion}

According to the potentiodynamic polarization test results (Table 6), it can be stated that the AISI 304L deep rolled samples, under both processing conditions (dry and cryogenic), exhibit better corrosion behavior with regard to the machined state. This result can be attributed to recrystallized grains at the surface and the near-surface regions after deep rolling (Figure 11). Indeed, it has been stated by previous investigations that grain refinement at the surface results 
in better resistance to uniform corrosion $[3,7]$, to pitting $[3,33]$ and enhances the stability of the passive film [3]. Nevertheless, the effects of the deep rolling environment must be detailed as controversial results depending on the deep rolling speed when dry and liquid nitrogen are considered. Actually, deep rolling under cryogenic cooling improves the corrosion behavior of the AISI 304L stainless steel machined surfaces, comparatively to the dry condition, for high deep rolling speeds only. This issue is discussed in the following based on results of previous investigations establishing that the corrosion behavior of metallic components is linked to many factors such as temperature, surface topography, microstructure, strain-induced martensite, surface hardening, residual stress, or a combination of thereof $[3,7,34,35]$.

In this work, it is shown that deep rolling process under cryogenic cooling induces higher rates of strain-induced martensite (Column $\mathrm{C}$ of Table 5), which can be detrimental due to the galvanic effect that occurs between two different phases (austenite and martensite). Many investigations [36-42] have put in evidence the negative effects of the increased volume fraction of strain-induced martensite. Mordyuk et al. [40] showed that the high amount of $\alpha^{\prime}$-martensite generated during the peening of AISI 321 lead to the galvanic effect between austenitic and martensitic phases. The study of Barbucci et al. [41] pointed out that the strain-induced martensite is harmful to the corrosion resistance of cold-rolled AISI 301 stainless steel in $1 \mathrm{M}$ $\mathrm{H}_{2} \mathrm{SO}_{4}$ solution. Moreover, Liu et al. [42] reported that the formation of martensite in the austenite matrix gives rise to a local corrosive galvanic cell that deteriorates the corrosion resistance of cold-rolled AISI 304L in sulfuric acid solution. Thus, the uniform and localized corrosion test results (Table 6) depict that the AISI 304L deep rolled at $25 \mathrm{~m} / \mathrm{min}$, showing the highest volume fraction of strain-induced martensite $(40 \%)$, has the weakest corrosion resistance. In addition, it was expected that the deep rolled samples at $75 \mathrm{~m} / \mathrm{min}$ and $120 \mathrm{~m} / \mathrm{min}$ under cryogenic cooling, with high amounts of $\alpha^{\prime}$-martensite, would exhibit poor corrosion resistance. However, it was seen that the corrosion behavior of the AISI 304L samples deep rolled under these conditions is significantly improved. Kumar et al. [35] pointed out that the pitting potential changes of cold-worked 304 in $0.1 \mathrm{NaCl}$ cannot be mainly related to the straininduced martensite but also to the effect of surface roughness, residual stresses, crystallographic structure or to combined effects of these parameters. In the present work, it is found that deep rolling at speeds of $75 \mathrm{~m} / \mathrm{min}$ and $120 \mathrm{~m} / \mathrm{min}$, under cryogenic cooling, results in a significant improvement of the surface quality characterized by the reduction of surface roughness (Column A of Table 5). These findings are in accordance with the study of Lee et al. [7] showing that that the ultrasonically peened AISI 304 specimen, with higher volume fraction of straininduced martensite than the shot peened specimen, exhibited better corrosion behavior in 0.5 
$\mathrm{M} \mathrm{H}_{2} \mathrm{SO}_{4}$ solution. The authors reported that this enhancement is mainly related to the decreased surface roughness after ultrasonic peening. In addition, Hong et al. [43] reported that smoother surface inhibits pit activation and growth by reducing the number of metastable pit sites. Nevertheless, deep rolling at $25 \mathrm{~m} / \mathrm{min}$ under cryogenic cooling generates a slight reduction of the surface roughness $\left(R_{a}=0.99 \mu \mathrm{m}\right)$ comparatively to dry condition $\left(R_{a}=1.03 \mu \mathrm{m}\right)$. The study of Rawal et al. [44] showed that the corrosion resistance of shot peened $12 \mathrm{wt} \% \mathrm{Cr}$ steel is deteriorated due to the increase in the surface roughness after peening. But, in this deep rolling condition (cryogenic, $\mathrm{V}=25 \mathrm{~m} / \mathrm{min}$ ), it is seen that the corrosion behavior of AISI 304L deep rolled samples was not mainly influenced by the surface roughness. In this framework, it is observed that processing at a deep rolling speed of $25 \mathrm{~m} / \mathrm{min}$ under cryogenic cooling generates higher additional surface work hardening $\left(562 \mathrm{HV}_{0.1}\right)$ than that reached at dry condition (506 $\mathrm{HV}_{0.1}$. Based on these findings, it is assumed that the deteriorated electrochemical behavior of deep rolled AISI 304L is associated to the high strengthening [11, 45-47]. Indeed, Pałka et al. [11] pointed out that high surface strengthening induced by increased cold work in X2CrNiMo stainless steel after burnishing lead to the decrease of corrosion resistance in $5 \mathrm{wt}$ \% citric acid solution. Barbucci et al. [45] studied the passive behavior of cold-worked AISI 304 in 1M sulfuric acid. The authors reported that the increased sensitivity to pitting corrosion is related to the high amount of dislocations and stacking faults occurring when the cold work increased. Fu et al. [47] showed that increasing cold work level up to $60 \%$ decreases the pitting corrosion resistance of high nitrogen stainless steel in $3.5 \% \mathrm{NaCl}$. In addition, it can be stated that the slight increase of surface work hardening (by around $45 \mathrm{HV}_{0.1}$ ) in the samples deep rolled at 75 $\mathrm{m} / \mathrm{min}$ and $120 \mathrm{~m} / \mathrm{min}$ under cryogenic cooling (Column B of Table 5) has no significant impact on their electrochemical behavior. However, under these deep rolling conditions, the nearsurface residual stress profiles (Figure 14) depict that the increase of surface compressive residual stresses (about $300 \mathrm{MPa}$ ) are shown to enhance their corrosion behavior significantly. Actually, the compressive residual stress distributions can be considered as a source for modifying the electrochemical behavior of AISI 304L deep rolled samples. The work of Takakuwa et al. [34] mentioned the beneficial effect of surface compressive residual stresses on the corrosion behavior of SUS316L in 5 wt. $\% \mathrm{H}_{2} \mathrm{SO}_{4}$. The work material was firstly subjected to several surface finish processes. Authors reported that the introduction of more compressive residual stress fields at the surface results in the growth and stability of the passivation film regardless of the surface condition. This was attributed to the decrease of interatomic spacing due to the surface compressive stresses. Nevertheless, it seems that the increase of surface compressive residual stress levels to $\sigma_{11}=-1128 \mathrm{MPa}$ and $\sigma_{22}=-683 \mathrm{MPa}$ 
after processing at a speed of $25 \mathrm{~m} / \mathrm{min}$ under cryogenic cooling is one of the main factors altering the corrosion behavior of AISI 304L samples. Indeed, Solomon et al. [36] reported that the presence of highly-compressive residual stress levels related to the martensitic transformation engender the rupture of the passive film.

Based on the foregoing, it is believed that the corrosion behavior of AISI 304L samples deep rolled at a speed of $25 \mathrm{~m} / \mathrm{min}$ under cryogenic cooling is mainly influenced by the high volume fraction of strain-induced martensite, that can be considered as the preponderant effect impacting the electrochemical properties of the treated specimen. At this deep rolling condition, as the surface roughness values remain almost unchanged, the deterioration of corrosion behavior is worsened by the increase of surface work hardening and the introduction of high compressive residual stress at the surface. In addition, the electrochemical behavior of AISI $304 \mathrm{~L}$ deep rolled at speeds of $75 \mathrm{~m} / \mathrm{min}$ and $120 \mathrm{~m} / \mathrm{min}$ under cryogenic condition is considerably improved with decreasing surface roughness despite the high amounts of $\alpha^{\prime}$ martensite generated at the surface. At these deep rolling conditions, the enhancement of corrosion resistance is also attributed to the increase of surface compressive residual stresses.

According to these findings, it can be concluded that the correlation between volume fraction of strain-induced martensite, surface work hardening and residual stresses can critically affect the corrosion behavior and the stability of passive film of AISI 304L deep rolled samples under cryogenic cooling. Moreover, it is found that the reduction of surface roughness is the key factor for improving the electrochemical behavior chloride environments.

\section{Conclusions}

An experimental investigation was performed to study the effects of deep rolling parameters, namely the work speed and the cooling mode, on the electrochemical behavior of AISI 304L components in chloride environment. The main findings of this study are summarized as follows:

a. Refined grains in the surface layers are produced by deep rolling process either with or without the application of liquid nitrogen. This grain refinement improves the corrosion behavior of deep rolled samples with regard to machined state.

b. An interrelated correlation between many factors such as surface roughness, straininduced martensite, surface microhardness and residual stresses is found to affect the corrosion behavior of deep rolled specimens. 
c. At a speed of $25 \mathrm{~m} / \mathrm{min}$, cryogenic deep rolled samples exhibit worse electrochemical behavior than those processed under dry condition. This deterioration is mainly attributed to:

- The high amount of strain-induced martensite (40\%) resulting in galvanic effect;

- The high plastic deformation, which leads to strain hardening, and thus, a considerable increase of the surface microhardness up to $562 \mathrm{HV}_{0.1}$.

- Highly-compressive residual stress distribution in the near-surface regions. The surface residual stress levels reaches about -1128 MPa in the longitudinal direction and -683 MPa in the transversal direction.

d. Although cryogenic deep rolling process induces high amounts of strain-induced martensite which is harmful to corrosion behavior due to galvanic effect, deep rolled samples performed at high speeds of $75 \mathrm{~m} / \mathrm{min}$ and $120 \mathrm{~m} / \mathrm{min}$ exhibit an enhanced resistance to uniform and localized corrosion regarding dry condition. This improvement was essentially related to:

- The reduction of surface roughness by retarding pit activation and growth. At a work speed of $120 \mathrm{~m} / \mathrm{min}$, cryogenic deep rolling reduces the arithmetic surface roughness by about $92 \%$ comparatively to the machined state.

- Beneficial compressive residual stress distributions in the near-surface layers. Regarding dry condition, cryogenic deep rolling at a speed of $75 \mathrm{~m} / \mathrm{min}$ produces maximum surface residual stress levels (319 MPa for $\sigma_{11}$ and 109 $\mathrm{MPa}$ for $\sigma_{22}$ ). 


\section{DECLARATIONS:}

- Ethical Approval: This article does not contain any studies with human participants or animals performed by any of the authors.

- Consent to Participate: This article does not contain any studies with human participants or animals performed by any of the authors.

- Consent to Publish: This article does not contain any studies with human participants or animals performed by any of the authors.

- Authors Contributions:

Khouloud Gharbi is a $\mathrm{PhD}$ student, and these are some of the results of here thesis. She conducted all the experiments and the observations.

Dr.Naoufel Ben Moussa: Supervised all the deep rolling experiments.

Dr. Amir Ben Rhouma: Supervised all the corrosion experiments.

Pr. Nabil Ben Fredj: Supervised all the work and corrected the paper. He is the supervisor of khouloud Gharbi.

- Funding: Not applicable.

- Competing Interests: The authors declare that they have no conflict of interest.

- Availability of data and materials: Not applicable. 


\section{Acknowledgement}

The authors would like to thank Caveo Automotive, particularly Mr. Imed Ben Rzouga, Mr. Sari Guimaji and Mr. Omar Mekni for their help with the residual stress measurements and SEM examinations.

\section{References}

1. Fontana M, N. Greene, and J. Klerer (1968) Corrosion Engineering. Journal of The Electrochemical Society. 115: p. 142C. https://doi.org/10.1149/1.2411256

2. Rustandi A, Nuradityatama, Rendi M, Setiawan S (2017) The use of cyclic polarization method for corrosion resistance evaluation of austenitic stainless steel 304L and 316L in aqueous sodium chloride solution. International Journal of Mechanical Engineering and Robotics Research. 6: p. 512-518. https://doi.org/10.18178/ijmerr.6.6.512-518

3. Toppo A, Kaul R, Pujar M, Mudali K, Kukreja L (2012) Enhancement of corrosion resistance of type 304 stainless steel through a novel thermo-mechanical surface treatment. Journal of Materials Engineering and Performance 22. https://doi.org/ 10.1007/s11665-012-0304-2

4. Asaduzzaman M.D, M. Mohammad, and M.M. Islam (2011) Effects of concentration of sodium chloride solution on the pitting corrosion behavior of AISI 304L austenitic stainless steel. Chemical Industry and Chemical Engineering Quarterly. 17: p. 477-483. https://doi.org/ 10.2298/ciceq110406032a

5. Tsouli S, Lekatou A.G, Kleftakis S, Matikas T.E, Dalla P.T (2018) Corrosion behavior of 304L stainless steel concrete reinforcement in acid rain using fly ash as corrosion inhibitor. Procedia Structural Integrity 10: p. 41-48. https://doi.org/10.1016/j.prostr.2018.09.007

6. Paredes E.C, Bautista A, Alvarez S.M, Velasco F (2012) Influence of the forming process of corrugated stainless steels on their corrosion behaviour in simulated pore solutions. Corrosion Science 58: p. 52-61. https://doi.org/10.1016/j.corsci.2012.01.010

7. Lee H.-s, Kim D.-s, Jung J.-s, Pyoun Y.-s, Shin K (2009) Influence of peening on the corrosion properties of AISI 304 stainless steel. Corrosion Science 51(12): p. 28262830. https://doi.org/10.1016/j.corsci.2009.08.008

8. Saada F.B, Antar Z, Elleuch K, Ponthiaux P, Gey N (2018) The effect of nanocrystallized surface on the tribocorrosion behavior of 304L stainless steel. Wear 394-395: p. 71-79. https://doi.org/10.1016/j.wear.2017.10.007

9. Lu J.Z, Qi H, Luo K. Y, Luo M, Cheng X.N (2014) Corrosion behaviour of AISI 304 stainless steel subjected to massive laser shock peening impacts with different pulse energies. Corrosion Science 80: p. 53-59. https://doi.org/10.1016/j.corsci.2013.11.003

10. Wei X, Zhang C, and Ling X (2017) Effects of laser shock processing on corrosion resistance of AISI 304 stainless steel in acid chloride solution. Journal of Alloys and Compounds 723: p. 237-242. https://doi.org/10.1016/j.jallcom.2017.06.283

11. Pałka K, Weroński A, Zaleski K (2006) Mechanical properties and corrosion resistance of burnished X5CrNi18-9 stainless steel. Journal of Achievements in Materials and Manufacturing Engineering 16(1-2): p. 57-62.

12. Biehler J, Hoche H, and Oechsner M (2017) Nitriding behavior and corrosion properties of AISI 304L and 316L austenitic stainless steel with deformation-induced martensite. 
$\begin{array}{lllll}\text { Surface } \text { and } \text { Coatings } & \text { Technology } 24 \text {-128. }\end{array}$ https://doi.org/10.1016/j.surfcoat.2017.05.059

13. Liang W (2003) Surface modification of AISI 304 austenitic stainless steel by plasma nitriding. Applied Surface Science 211(1): p. 308-314. https://doi.org/10.1016/S01694332(03)00260-5

14. Pu Z, Song G. L, Yang S, Outeiro J. C, Dillon O. W, Puleo D. A, Jawahir I. S (2012) Grain refined and basal textured surface produced by burnishing for improved corrosion performance of AZ31B Mg alloy. Corrosion Science 57(Supplement C): p. 192-201. https://doi.org/10.1016/j.corsci.2011.12.018

15. Yang S, Umbrello D, Dillon O.W, Puleo D. A, Jawahir I. S (2015) Cryogenic cooling effect on surface and subsurface microstructural modifications in burnishing of $\mathrm{Co}-\mathrm{Cr}-$ Mo biomaterial. Journal of Materials Processing Technology 217: p. 211-221. https://doi.org/10.1016/j.jmatprotec.2014.11.004

16. Caudill J, Huang B, Arvin C, Schoop J, Meyer K, Jawahir I. S (2014) Enhancing the Surface Integrity of Ti-6Al-4V Alloy through Cryogenic Burnishing. Procedia CIRP 13(Supplement C): p. 243-248. https://doi.org/10.1016/j.procir.2014.04.042

17. Muñoz-Cubillos J, Coronado J.J, and Rodríguez S.A (2017) Deep rolling effect on fatigue behavior of austenitic stainless steels. International Journal of Fatigue 95: p. 120-131. http://doi.org/10.1016/j.ijfatigue.2016.10.008

18. Nikitin I. and Altenberger I (2007) Comparison of the fatigue behavior and residual stress stability of laser-shock peened and deep rolled austenitic stainless steel AISI 304 in the temperature range $25-600^{\circ} \mathrm{C}$. Materials Science and Engineering: A 465(1): p. 176-182. https://doi.org/10.1016/j.msea.2007.02.004

19. Ben Moussa N, Gharbi K, Chaieb I, Ben Fredj N (2018) Improvement of AISI 304 austenitic stainless steel low-cycle fatigue life by initial and intermittent deep rolling. The International Journal of Advanced Manufacturing Technology 101(1): p. 435-449. https://doi.org/10.1007/s00170-018-2955-0

20. Manimaran G, Pradeep kumar M and Venkatasamy R (2014) Influence of cryogenic cooling on surface grinding of stainless steel 316. Cryogenics 59: p. 76-83. https://doi.org/10.1016/j.cryogenics.2013.11.005

21. Ben Moussa N, Sidhom H and Braham C (2012) Numerical and experimental analysis of residual stress and plastic strain distributions in machined stainless steel. International journal of mechanical sciences 64(1): p. 82-93. http://dx.doi.org/10.1016/j.ijmecsci.2012.07.011

22. Jafari Tadi Abdolreza (2017) Formation of surface nano/ultrafine structure using deep rolling process on the AISI $316 \mathrm{~L}$ stainless steel 1. https://doi.org/10.15406/mseij.2017.01.00015

23. Sato M, Tsuji N, Minaminob Y and Koizumi Y (2004) Formation of nanocrystalline surface layers in various metallic materials by near surface severe plastic deformation. Science and Technology of Advanced Materials 5(1-2): p. 145-152. https://doi.org/10.1016/j.stam.2003.10.015

24. Han H, Lee C, Suh D.-W, Kim S.-J (2008) A microstructure-based analysis for transformation induced plasticity and mechanically induced martensitic transformation. Materials Science and Engineering: A 485: p. 224-233. https://doi.org/10.1016/j.msea.2007.08.022

25. Huang B, Kaynak Y, Sun Y, Jawahir I. S (2015) Surface layer modification by cryogenic burnishing of Al 7050-T7451 alloy and validation with FEM-based burnishing model. Procedia CIRP 31: p. https://doi.org/10.1016/j.procir.2015.03.097 
26. Tourki Z, Bargui H and Sidhom H (2005) The kinetic of induced martensitic formation and its effect on forming limit curves in the AISI 304 stainless steel. Journal of Materials $\begin{array}{llll}\text { Processing } & \text { Technology 330-336. }\end{array}$ http://dx.doi.org/10.1016/j.jmatprotec.2003.08.010

27. Forouzan F, Najafizadeh A, Kermanpur A, Hedayati A, Surkialiabad R (2010) Production of nano/submicron grained AISI 304L stainless steel through the martensite reversion process. Materials Science and Engineering: A 527(27): p. 7334-7339. https://doi.org/10.1016/j.msea.2010.08.002

28. Yahyaoui H, Ben Moussa N, Braham C, Ben Fredj N, Sidhom H (2015) Role of machining defects and residual stress on the AISI 304 fatigue crack nucleation. Fatigue \& Fracture of Engineering Materials \& Structures 38(4): p. 420-433. https://doi.org/10.1111/ffe.12243

29. Prevéy P.S. and Cammett J.T (2004) The influence of surface enhancement by low plasticity burnishing on the corrosion fatigue performance of AA7075-T6. International Journal of Fatigue 26(9): p. 975-982. http://dx.doi.org/10.1016/j.ijfatigue.2004.01.010

30. Amdouni H, Bouzaiene H, Montagne A, Nasri M, Iost A (2017) Modeling and optimization of a ball-burnished aluminum alloy flat surface with a crossed strategy based on response surface methodology. The International Journal of Advanced Manufacturing Technology 88(1): p. 801-814. https://doi.org/10.1007/s00170-0168817-8

31. Wojciech S.O, Kurc-Lisiecka A and Kciuk M (2010) Effect of deformation-induced martensite on the microstructure, mechanical properties and corrosion resistance of X5CrNi18-8 stainless steel. Archives of Materials Science and Engineering 43.

32. Ben Fredj N, Sidhom H and Braham C (2006) Ground surface improvement of the austenitic stainless steel AISI 304 using cryogenic cooling. Surface and Coatings Technology 200(16): p. 4846-4860. https://doi.org/10.1016/j.surfcoat.2005.04.050

33. Li H, Jiang Z, Ma Q, Li Z (2011) Influence of cold working and grain size on pitting corrosion resistance of ferritic stainless steel. Advanced Materials Research 217-218: p. 1180-1184. https://doi.org/10.4028/www.scientific.net/AMR.217-218.1180

34. Takakuwa O and Soyama H (2015) Effect of residual stress on the corrosion behavior of austenitic stainless steel. Advances in Chemical Engineering and Science 05: p. 6271. https://doi.org/10.4236/aces.2015.51007

35. Kumar B, Mahato B, and Singh R (2007) Influence of cold-worked structure on electrochemical properties of austenitic stainless steels. Metallurgical and Materials Transactions A 38: p. 2085-2094. https://doi.org/10.1007/s11661-007-9224-4

36. Solomon N and Solomon I (2017) Effect of deformation-induced phase transformation on AISI 316 stainless steel corrosion resistance. Engineering Failure Analysis 79: p. 865-875. https://doi.org/10.1016/j.engfailanal.2017.05.031

37. Monrrabal G, Bautista A, Guzman S, Gutierrez C, Velasco F (2018) Influence of the cold working induced martensite on the electrochemical behavior of AISI 304 stainless steel surfaces. Journal of Materials Research and Technology 8. https://doi.org/10.1016/j.jmrt.2018.10.004

38. Abreu H.F.G.d, Carvalho S.S.d, Lima Neto P.d et al (2007) Deformation induced martensite in an AISI 301LN stainless steel: characterization and influence on pitting corrosion resistance. Materials Research 10: p. 359-366.

39. Lv J and Luo H (2014) Effects of strain and strain-induced $\alpha^{\prime}$-martensite on passive films in AISI 304 austenitic stainless steel. Materials science \& engineering. C, Materials for biological applications 34C: p. 484-490. https://doi.org/10.1016/j.msec.2013.10.003 
40. Mordyuk B.N, Prokopenko G.I, Vasylyev M.A, Iefimov M.O (2007) Effect of structure evolution induced by ultrasonic peening on the corrosion behavior of AISI-321 stainless steel. Materials Science and Engineering: A 458(1): p. 253-261. https://doi.org/10.1016/j.msea.2006.12.049

41. Barbucci A, Delucchi M, Panizza M, Sacco M, Cerisola G (2001) Electrochemical and corrosion behaviour of cold rolled AISI 301 in $1 \mathrm{M} \mathrm{H}_{2} \mathrm{SO}_{4}$. Journal of Alloys and Compounds 317-318: p. 607-611. https://doi.org/10.1016/S0925-8388(00)01396-7

42. Liu E, Zhang Y, Zhu L, Zeng Z, Gao R (2017) Effect of strain-induced martensite on the tribocorrosion of AISI 316L austenitic stainless steel in seawater. RSC Advances 7(71): p. 44923-44932. https://doi.org/10.1039/c7ra07318f

43. Hong $\mathrm{T}$ and Nagumo M (1997) Effect of surface roughness on early stages of pitting corrosion of Type 301 stainless steel. Corrosion Science 39(9): p. 1665-1672. https://doi.org/10.1016/S0010-938X(97)00072-3

44. Rawat M, Jayaraman TR, Prasad CRK, Kalpana Y (1999) Influence of shot peening on corrosion properties of steam turbine blading steel. The 7th International Conference on Shot Peening, Warsaw.

45. Barbucci A, Cerisola G and Cabot P (2002) Effect of cold-working in the passive behavior of 304 stainless steel in sulfate media. Journal of The Electrochemical Society - J ELECTROCHEM SOC 149. https://doi.org/10.1149/1.1516774

46. Feng X, Lu X, Zuo Y, Zhuang N, Chen D (2015) The effect of deformation on metastable pitting of 304 stainless steel chloride contaminated concrete pore solution. Corrosion Science 103. https://doi.org/10.1016/j.corsci.2015.11.022

47. Fu Y, Wu X, Han E, Ke W, Yang K, Jiang Z (2008) Influence of cold work on pitting corrosion behavior of a high nitrogen stainless steel. Journal of The Electrochemical Society - J ELECTROCHEM SOC 155. https://doi.org/10.1149/1.2939213 


\section{Figures}

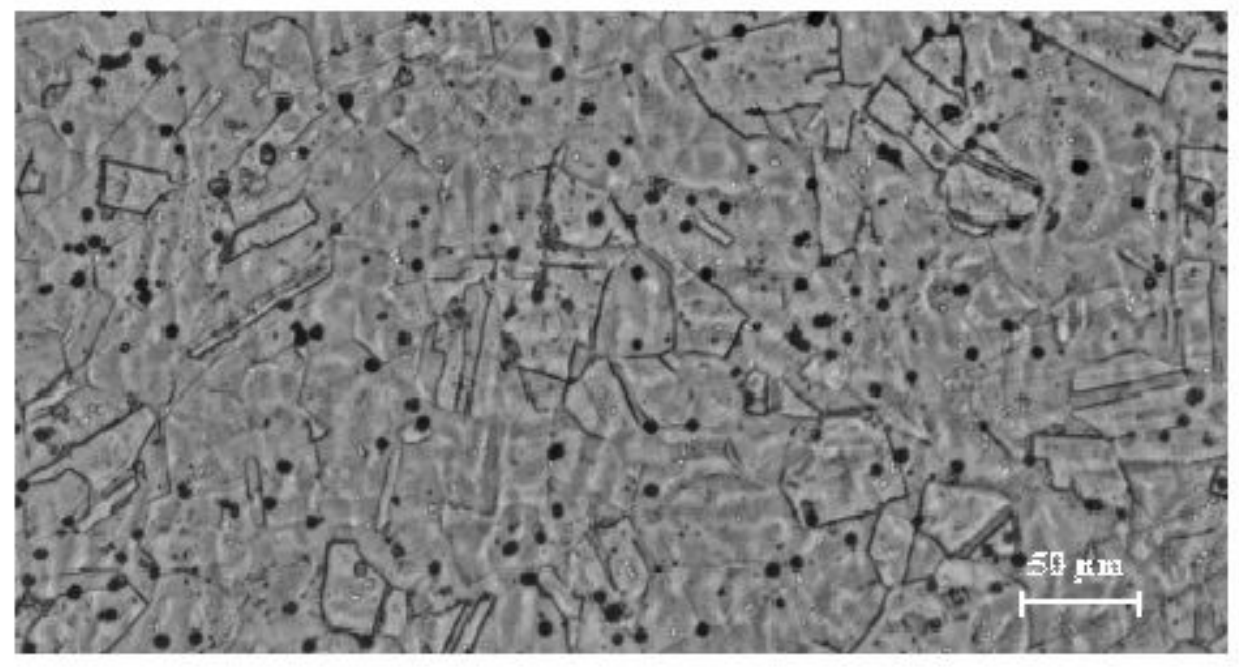

Figure 1

Microstructure of the tested AISI 304L stainless steel

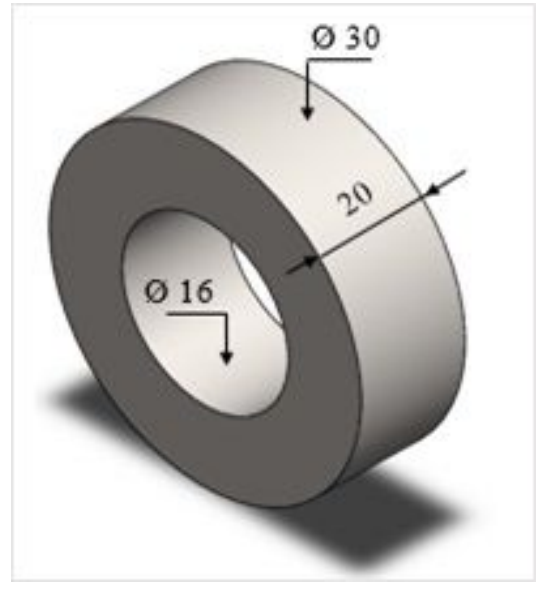

Figure 2

Workpiece geometry (mm) 


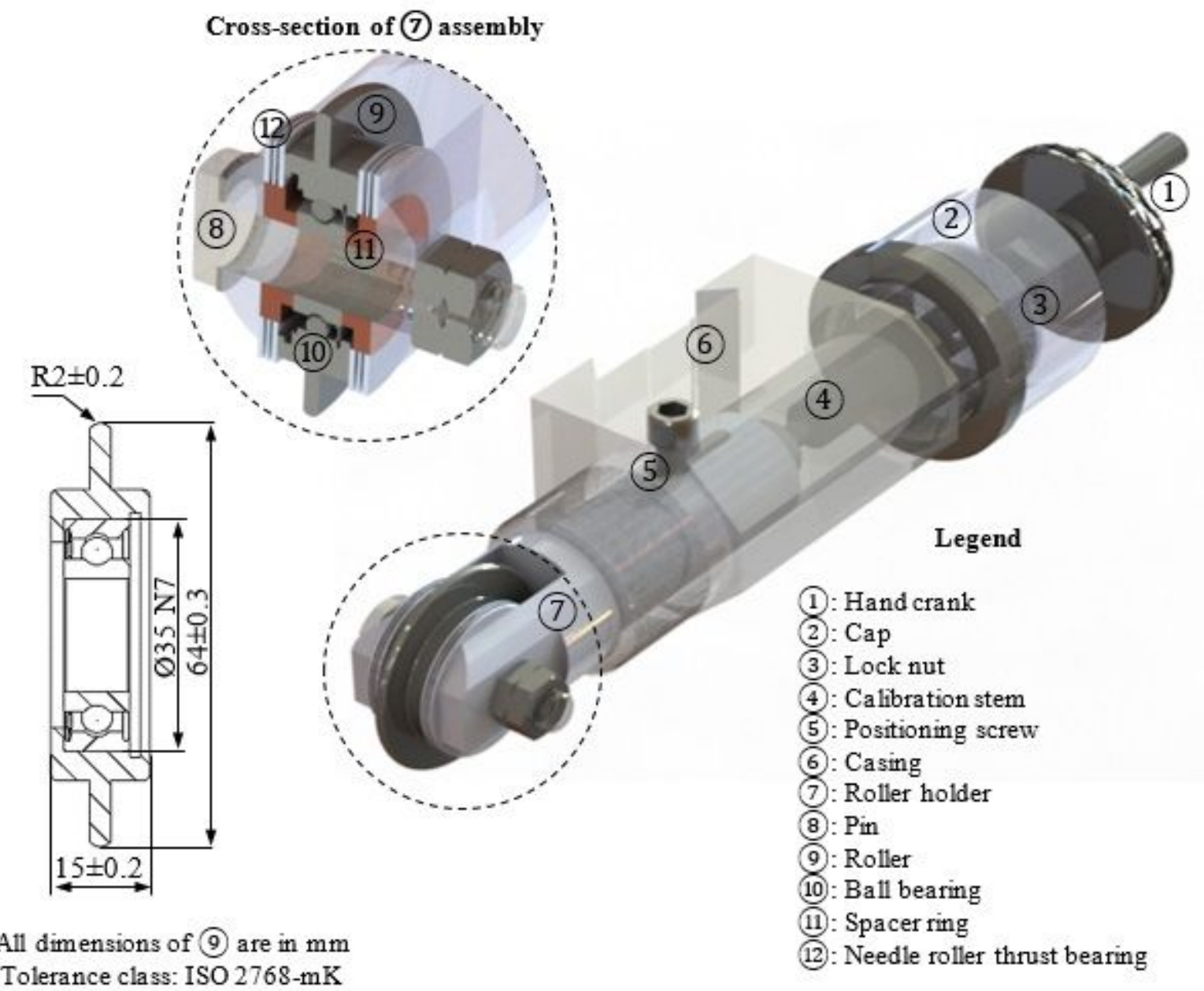

\section{Figure 3}

Details of the deep rolling tool

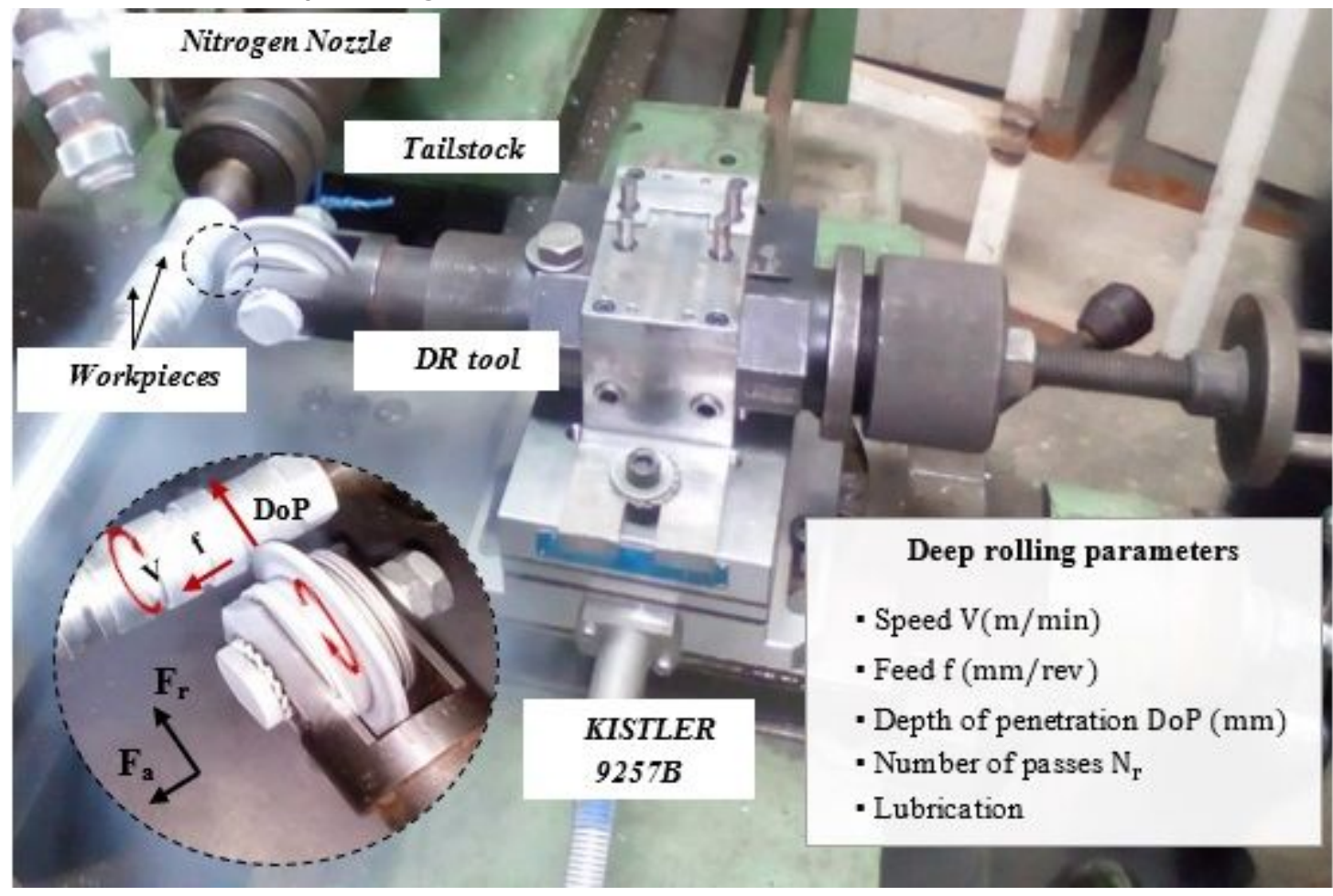


Figure 4

Deep rolling set-up (Fr and Fa are radial and axial DR forces)

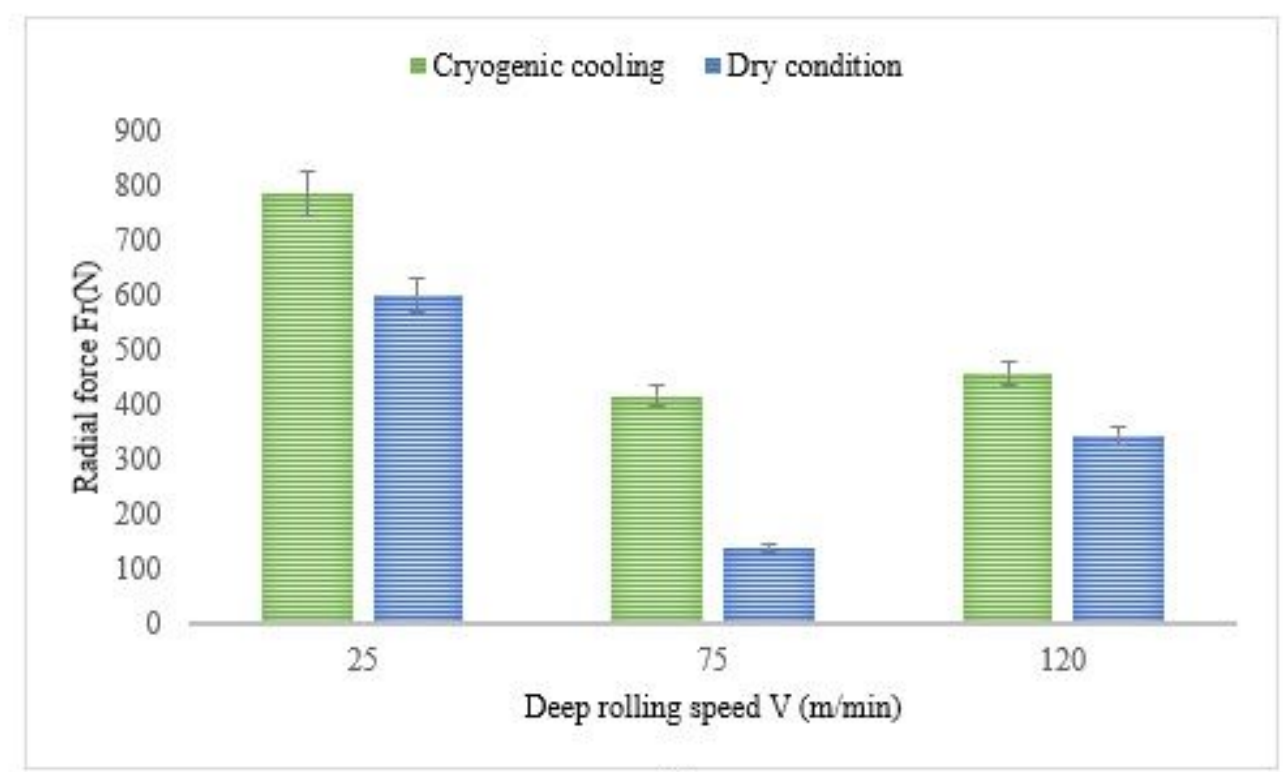

(a)

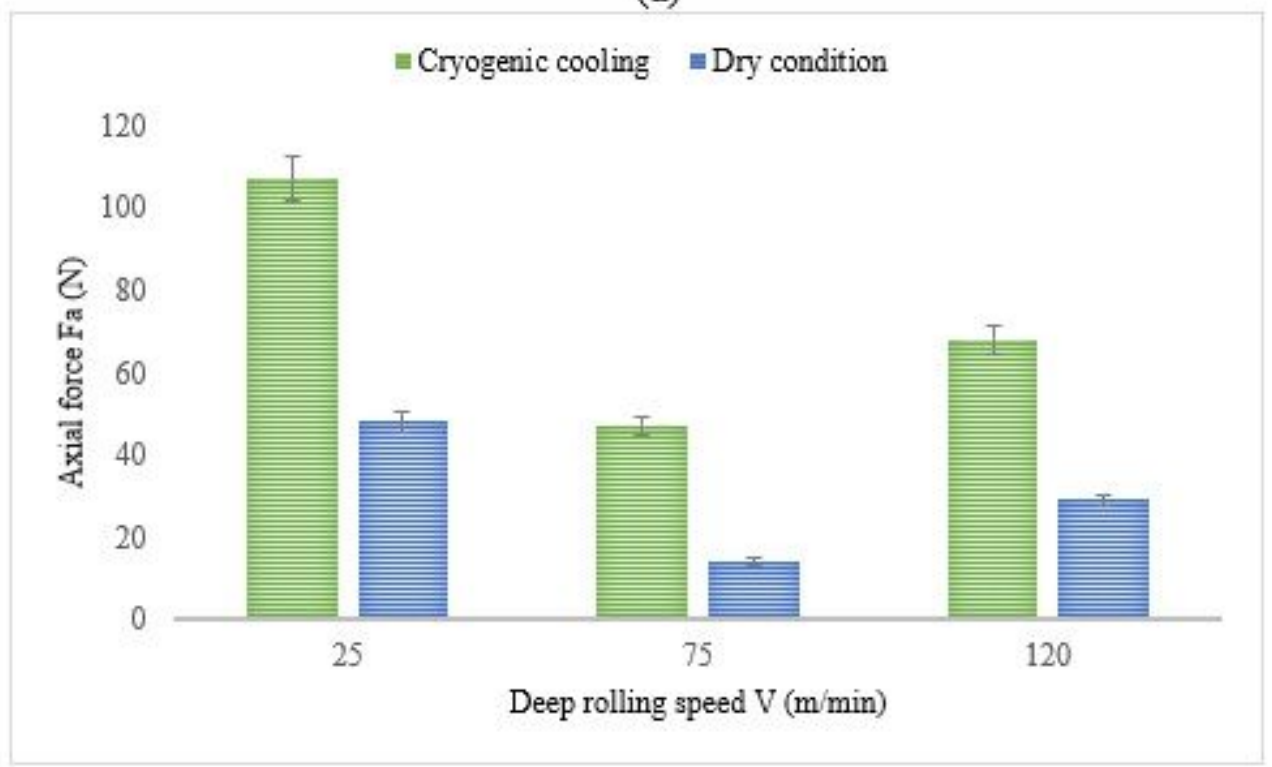

(b)

Figure 5

Effect of the cooling mode on (a) the DR radial force and (b) the DR axial force 


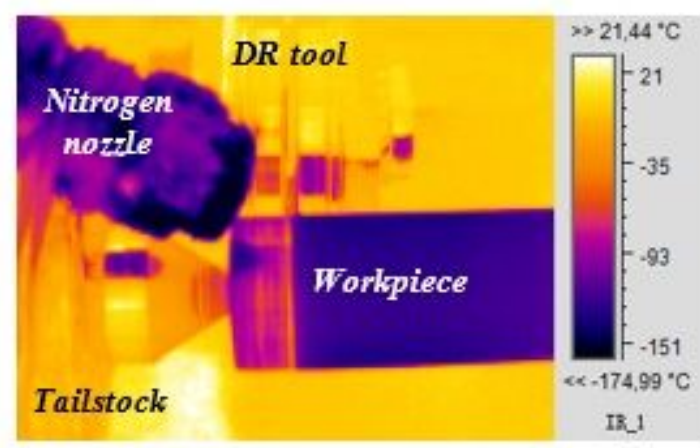

(a) at $25 \mathrm{~m} / \mathrm{min}$

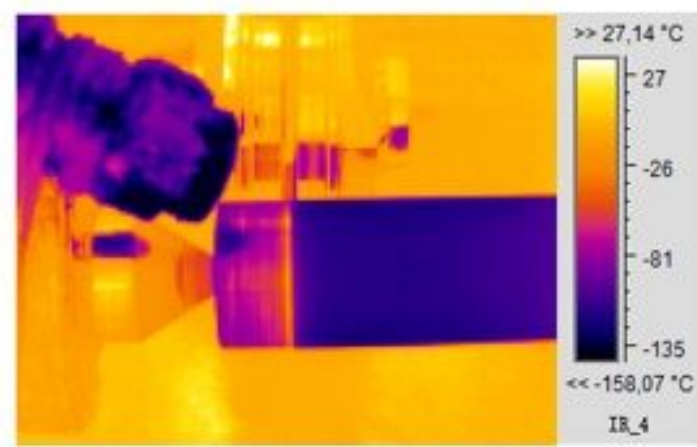

(b) at $75 \mathrm{~m} / \mathrm{min}$

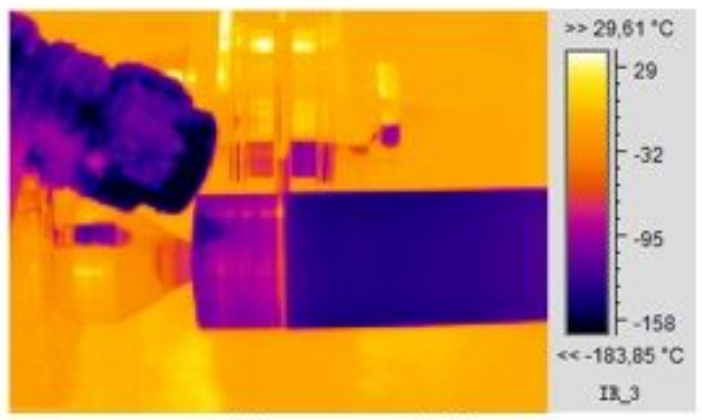

(c) at $120 \mathrm{~m} / \mathrm{min}$

\section{Figure 6}

Effect of cryogenic cooling mode and work speed on the deep rolling temperature

$\equiv$ Dry condition $\equiv$ Cryogenic cooling

60

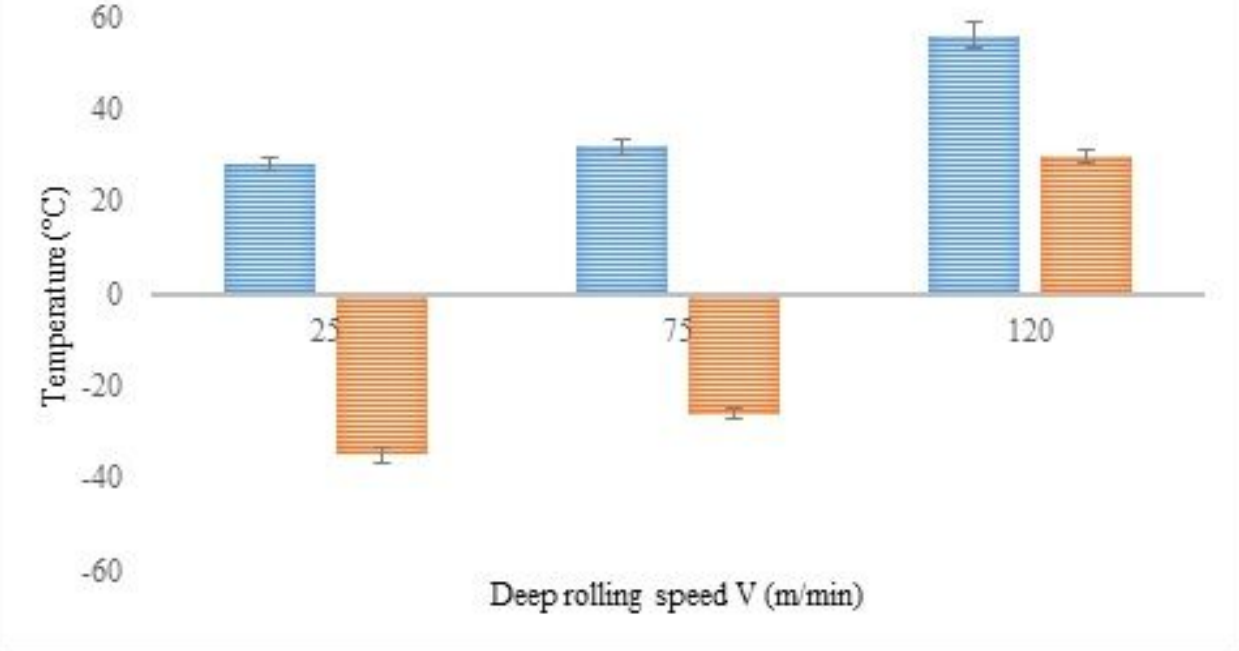

\section{Figure 7}

Effect of the cooling mode on the deep rolling temperature at the roller-workpiece contact point 


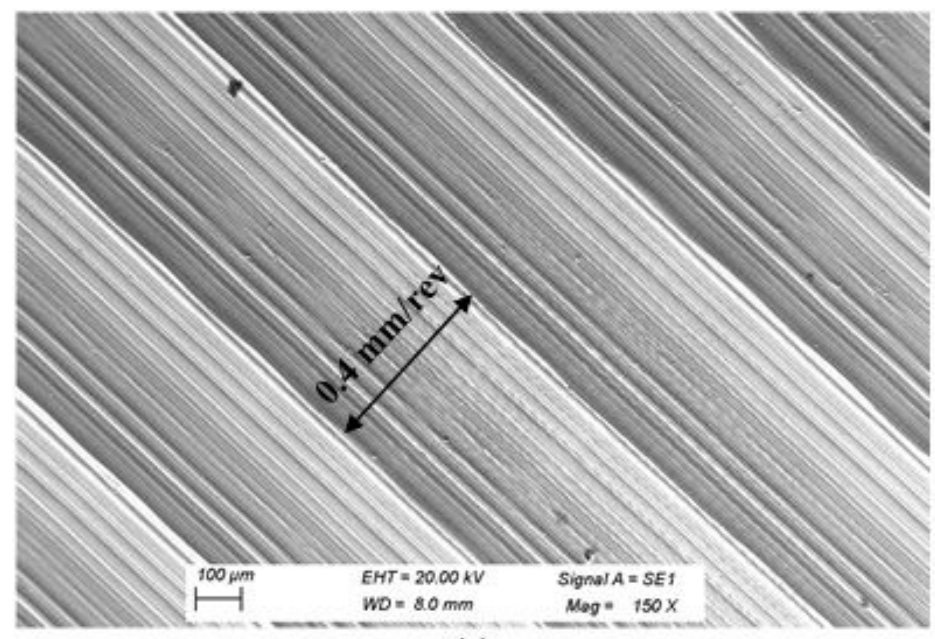

(a)

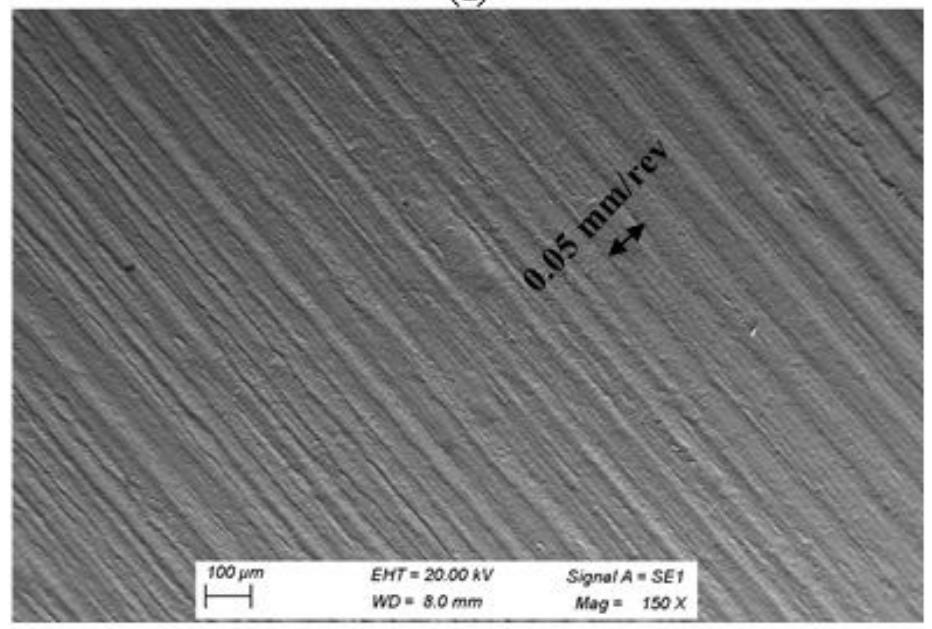

(b)

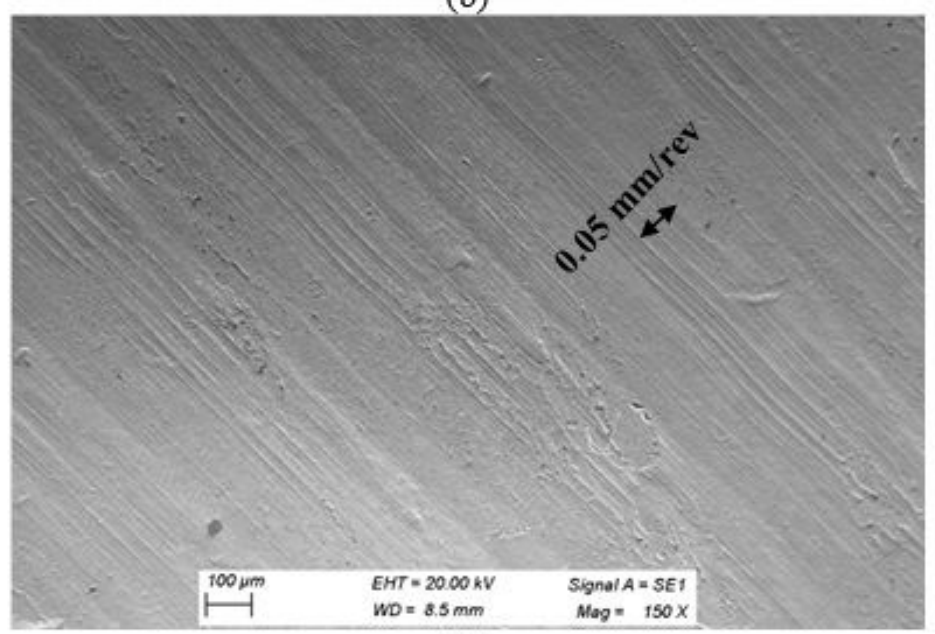

(c)

Figure 8

SEM observations of machined and deep rolled specimens a) machined b) deep rolled under dry condition at $120 \mathrm{~m} / \mathrm{min}$ c) deep rolled under cryogenic conditions at $120 \mathrm{~m} / \mathrm{min}$ 


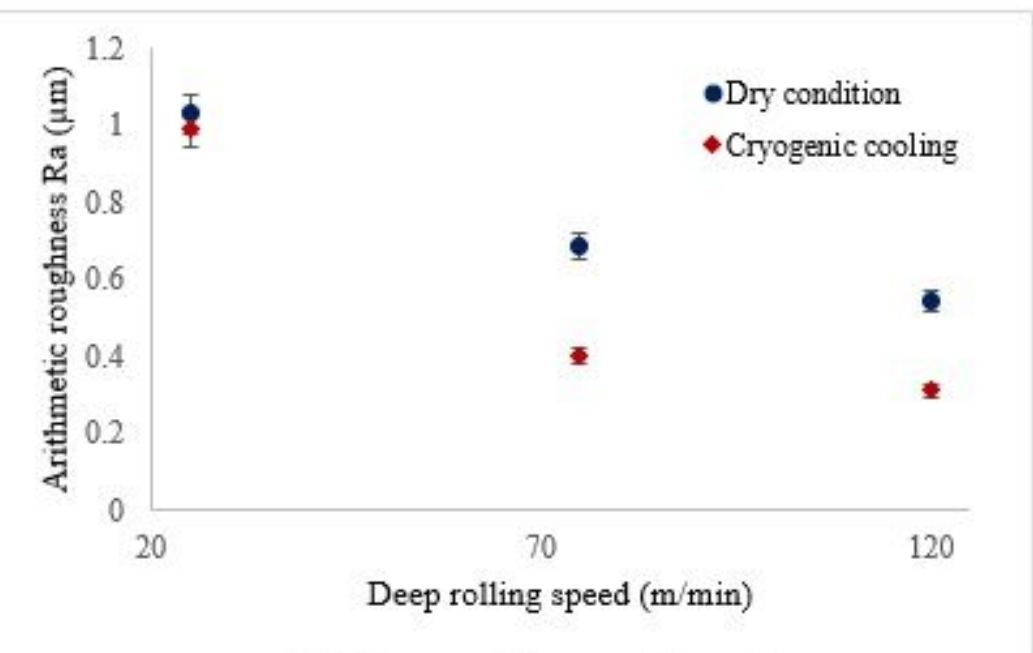

(a) Mean surface roughness $R_{3}$

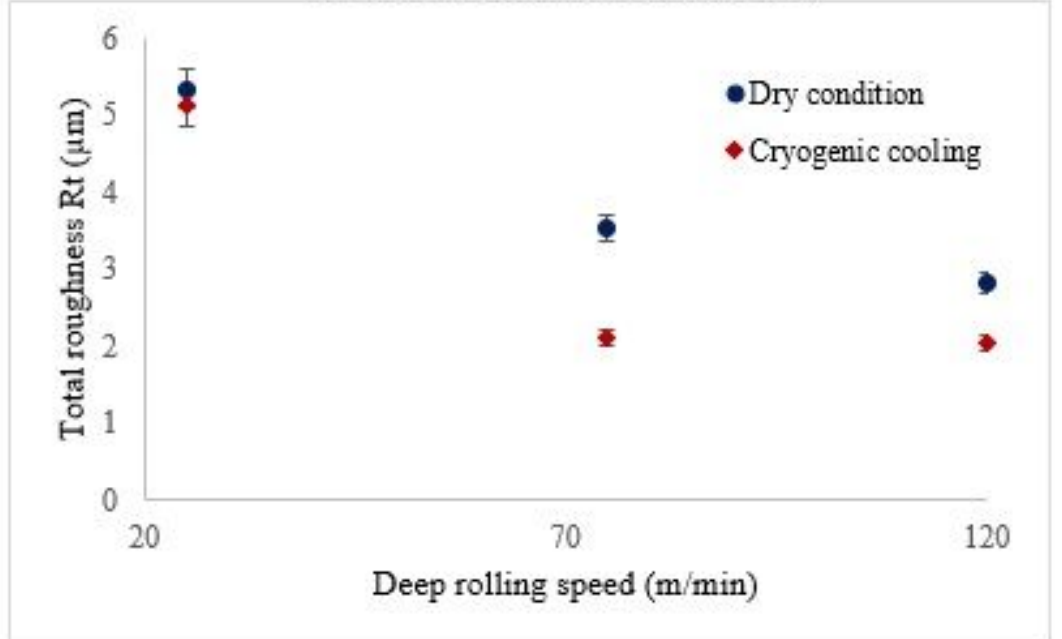

(b) Total surface roughness $R_{t}$

Figure 9

Effects of the cooling mode on the surface roughness of deep rolled surfaces of the AISI 304L Stainless Steel 


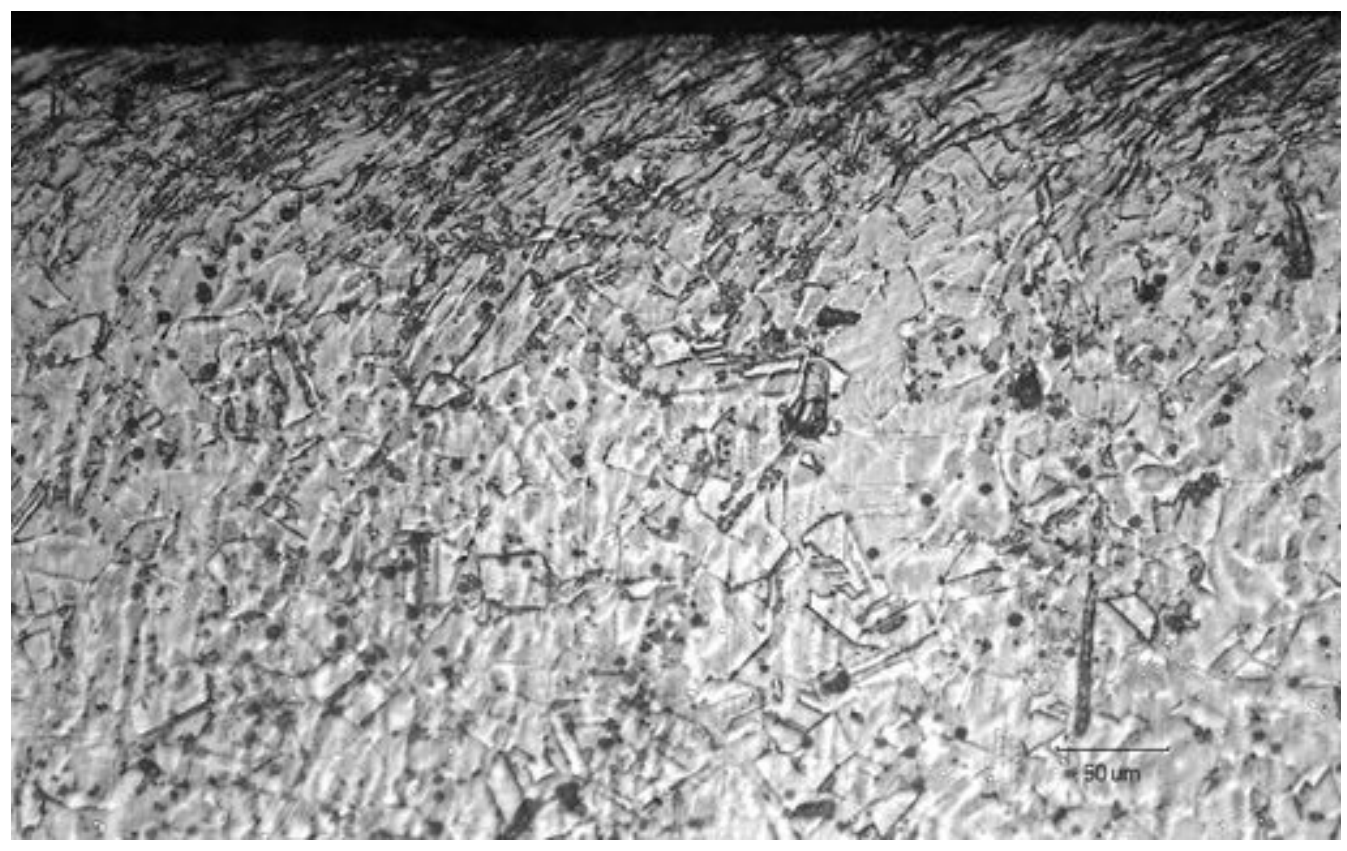

Figure 10

Cross section micrograph of the machined AISI 304L sample 

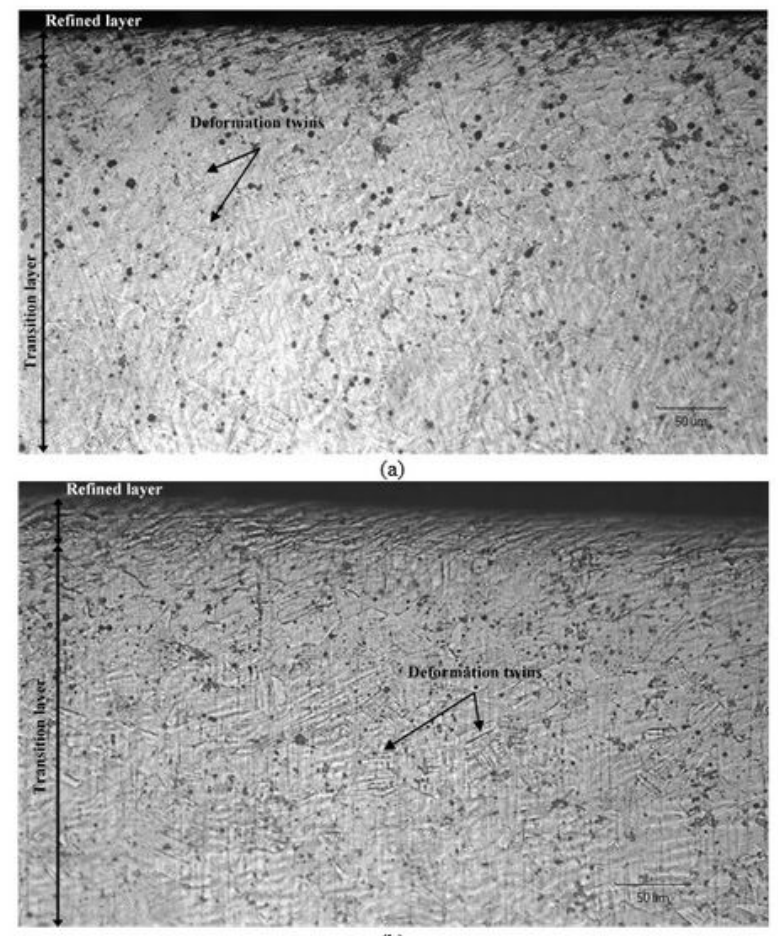

(b)
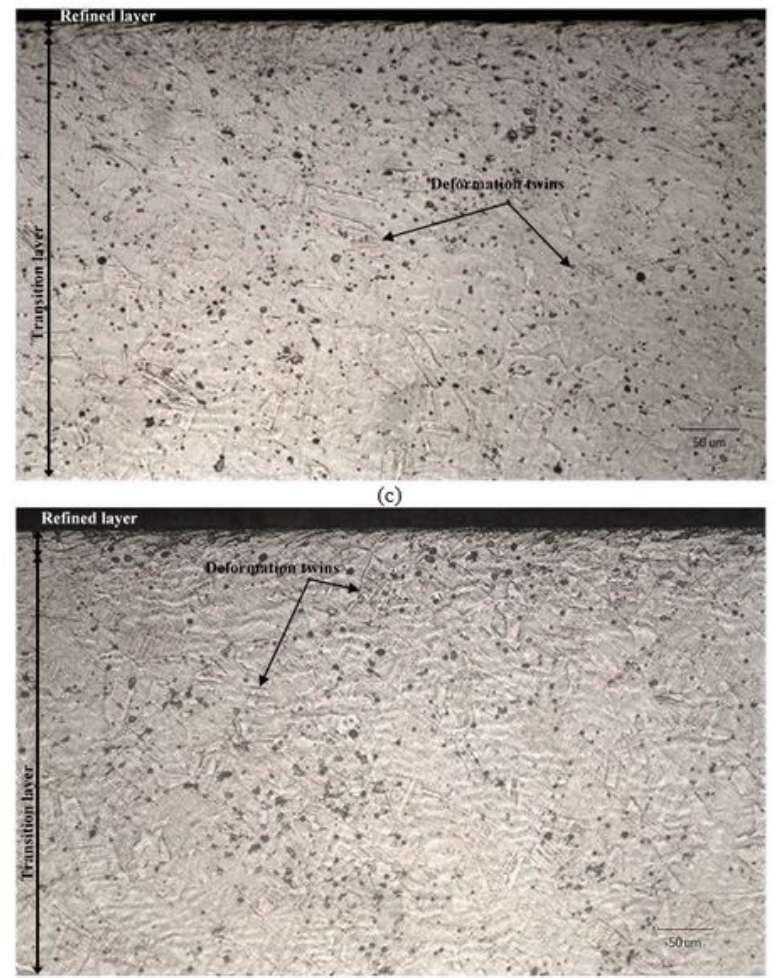

(d)

\section{Figure 11}

Cross section micrographs of deep rolled AISI 304L samples : (a) dry at $25 \mathrm{~m} / \mathrm{min}$, (b) Cryogenic at 25 $\mathrm{m} / \mathrm{min}$, (c) dry at $120 \mathrm{~m} / \mathrm{min}$ and (d) cryogenic at $120 \mathrm{~m} / \mathrm{min}$ 


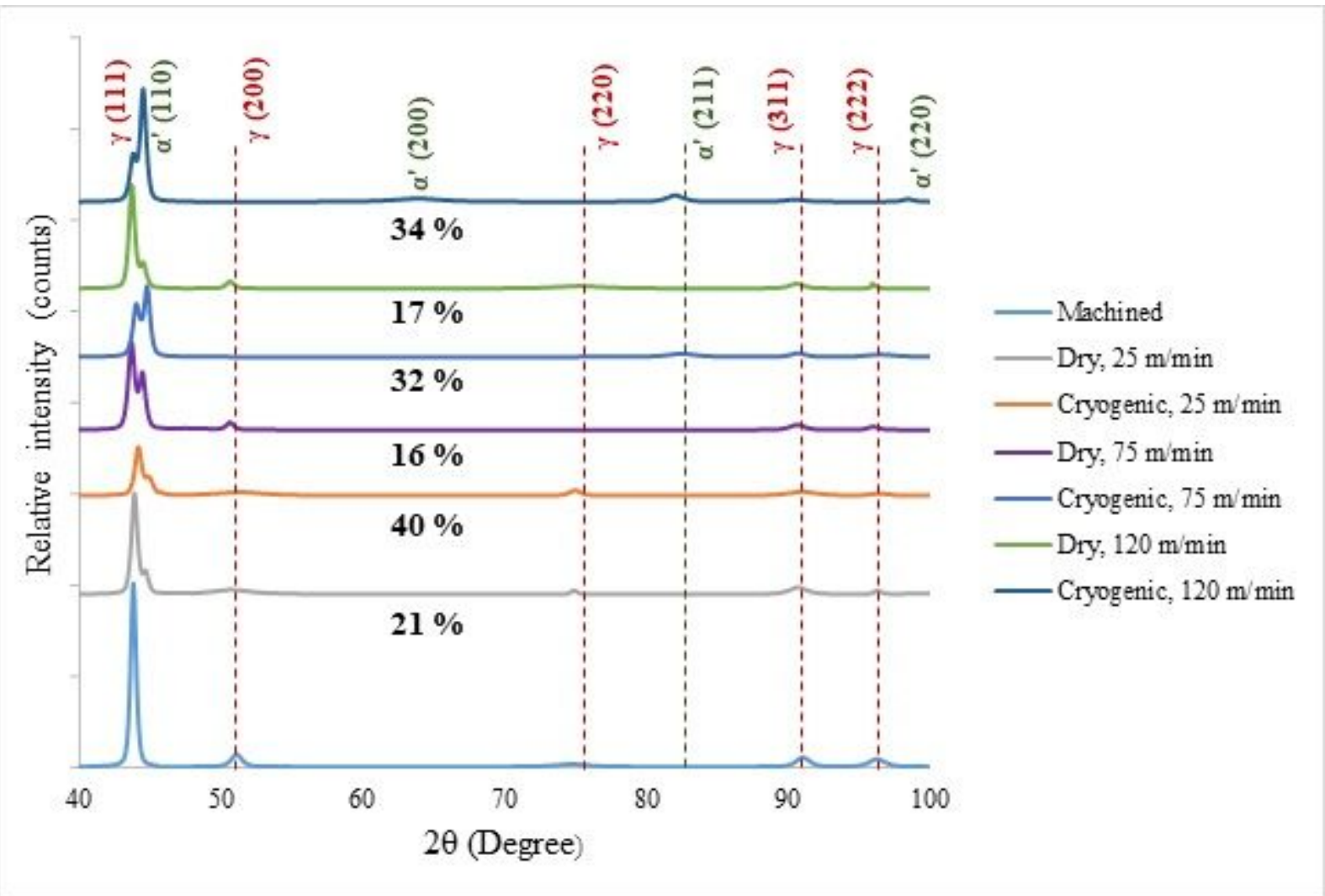

Figure 12

XRD spectra of machined and deep rolled AISI 304L surfaces with the volume fractions of strain-induced martensite 


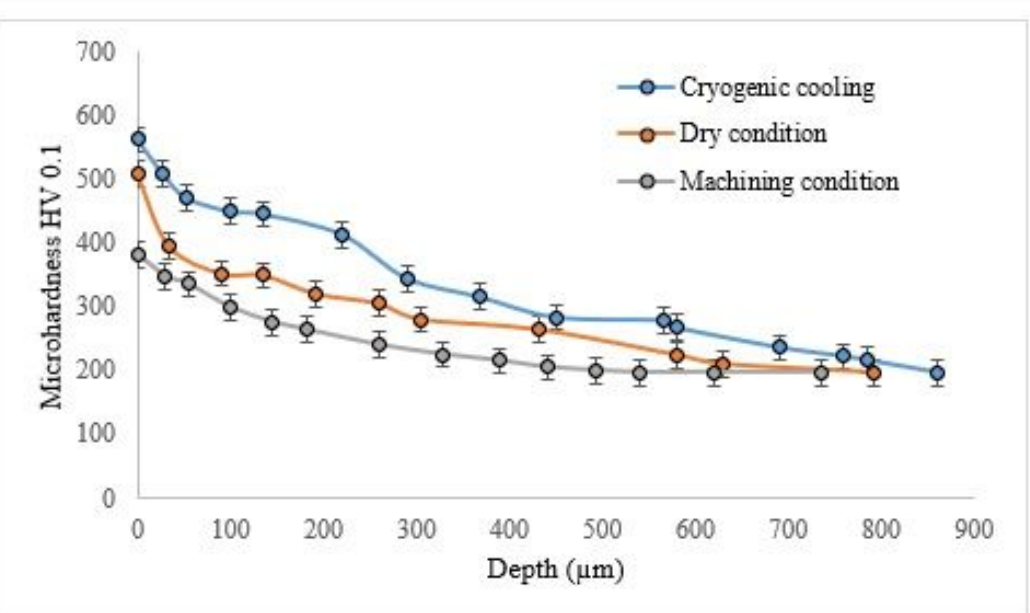

(a)

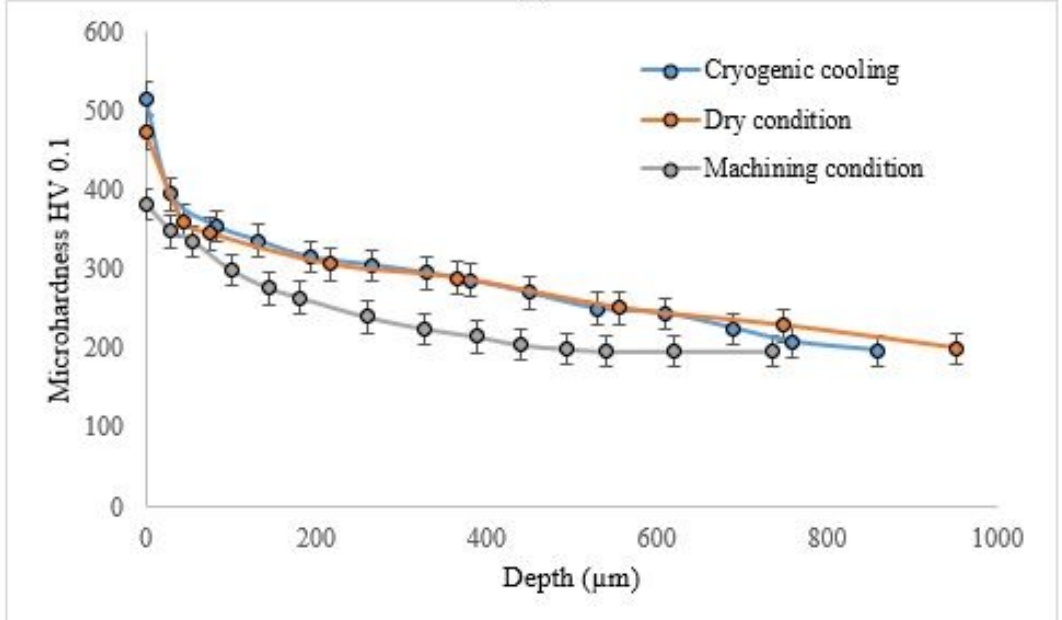

(b)

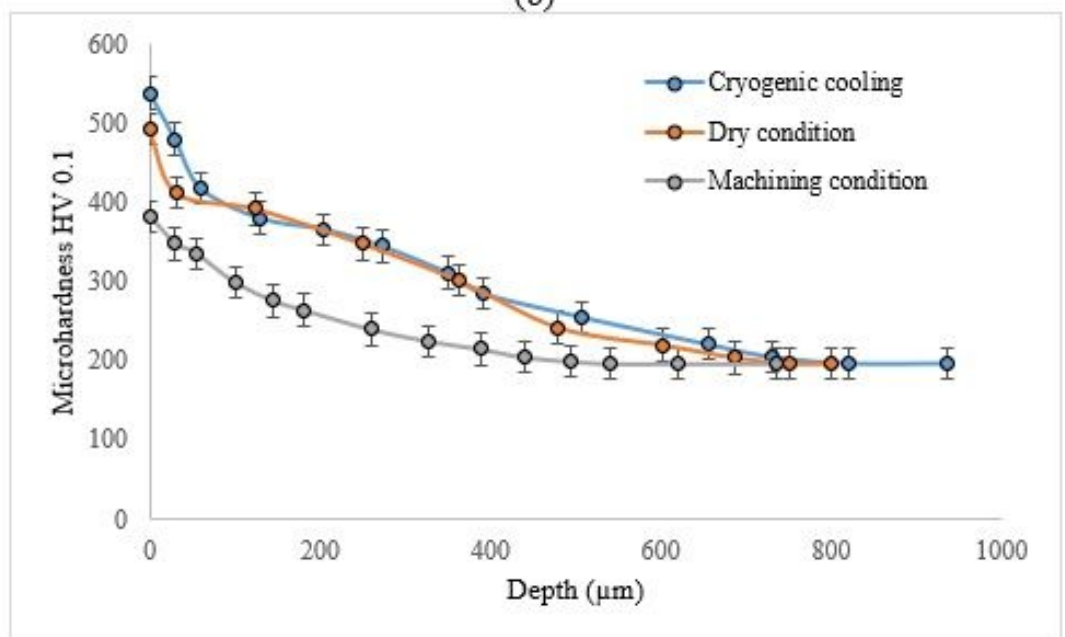

(c)

\section{Figure 13}

Microhardness profiles of the AISI 304L samples deep rolled at (a) $25 \mathrm{~m} / \mathrm{min}$, (b) $75 \mathrm{~m} / \mathrm{min}$ and (c) 120 $\mathrm{m} / \mathrm{min}$ 


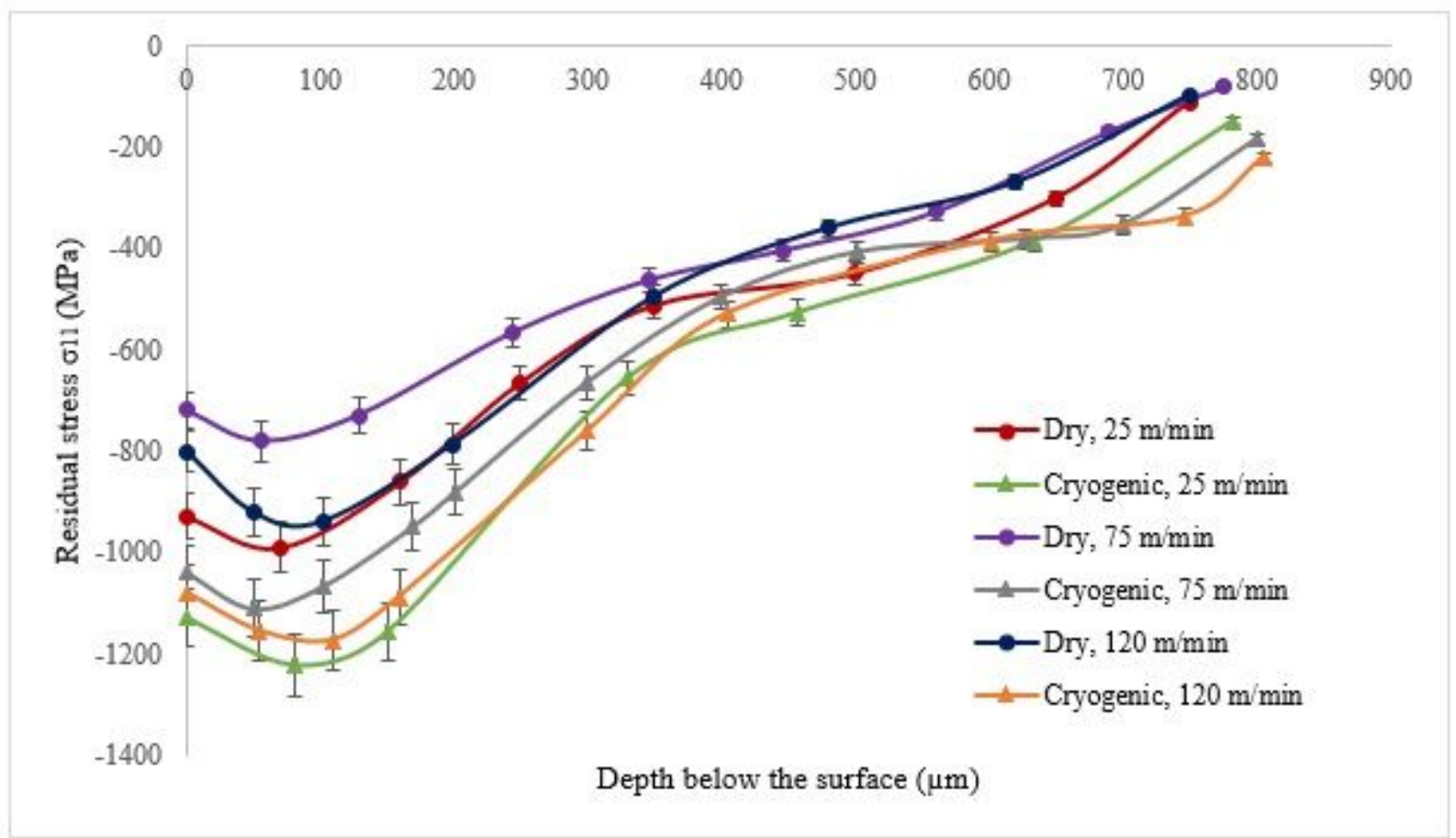

(a)

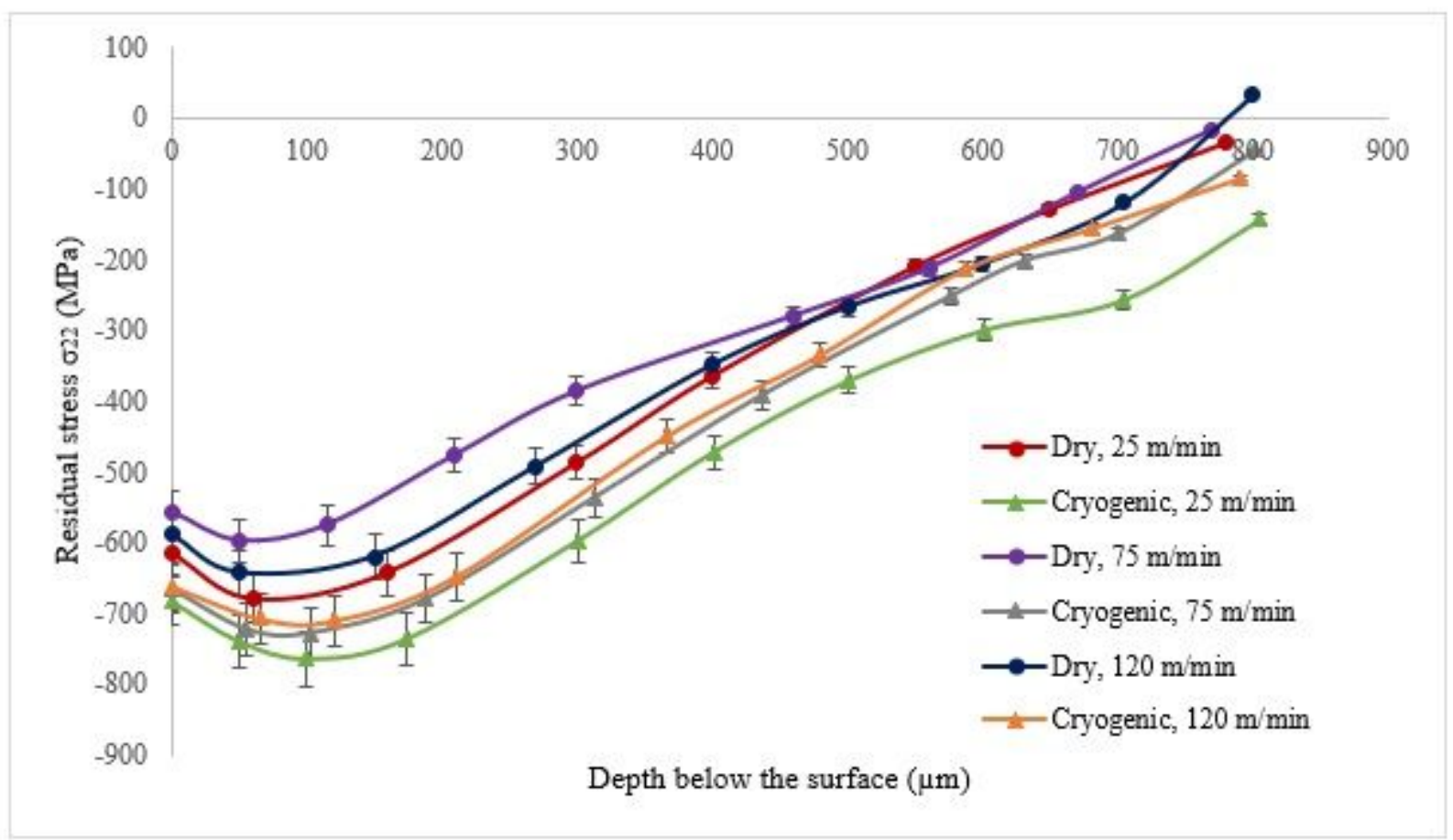

(b)

\section{Figure 14}

Effect of deep rolling on the residual stress profiles in (a) the longitudinal direction $\sigma 11$ and (b) the transverse direction $\sigma 22$ 


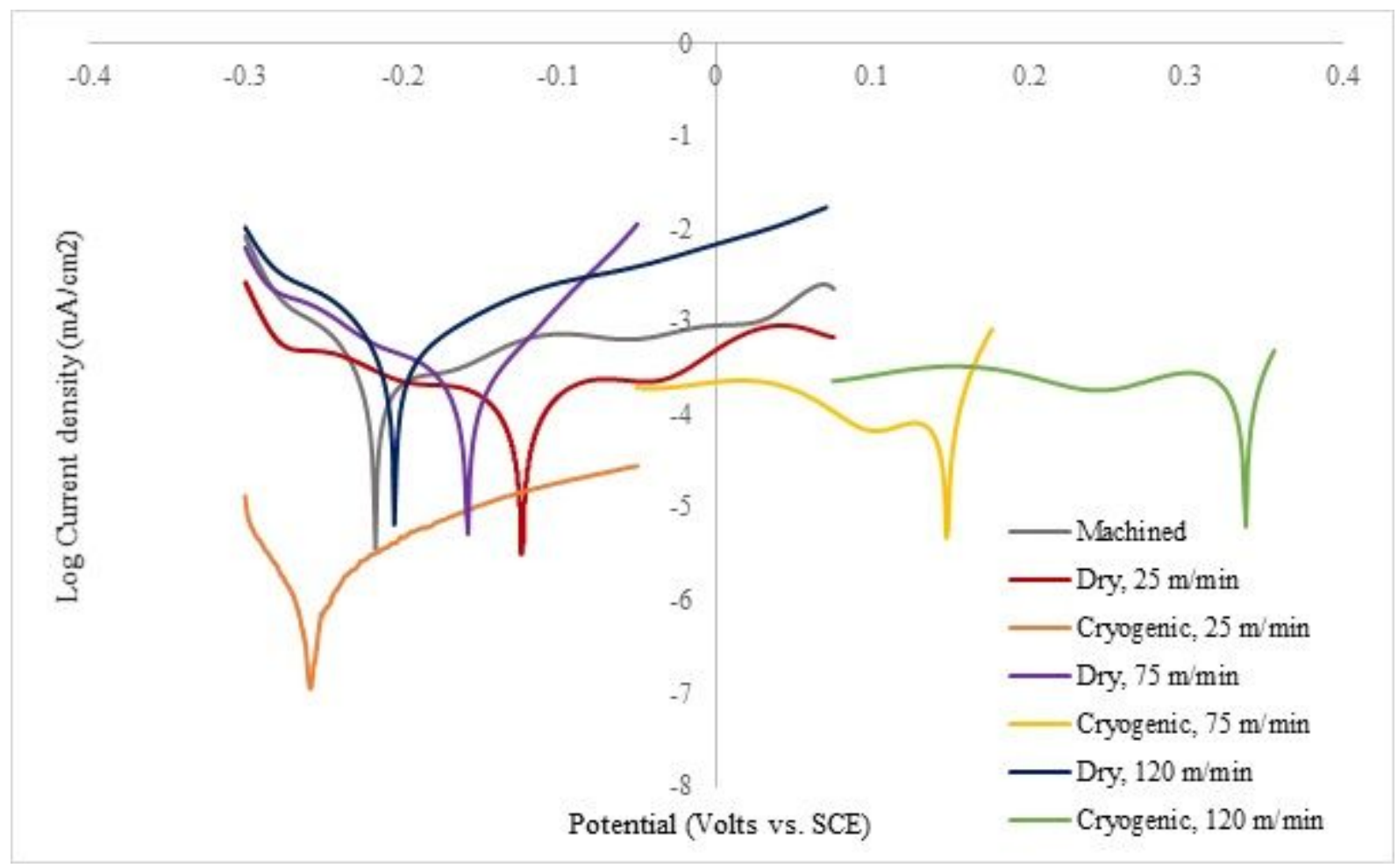

Figure 15

Potentiodynamic polarization curves of machined and deep rolled samples in synthetic seawater

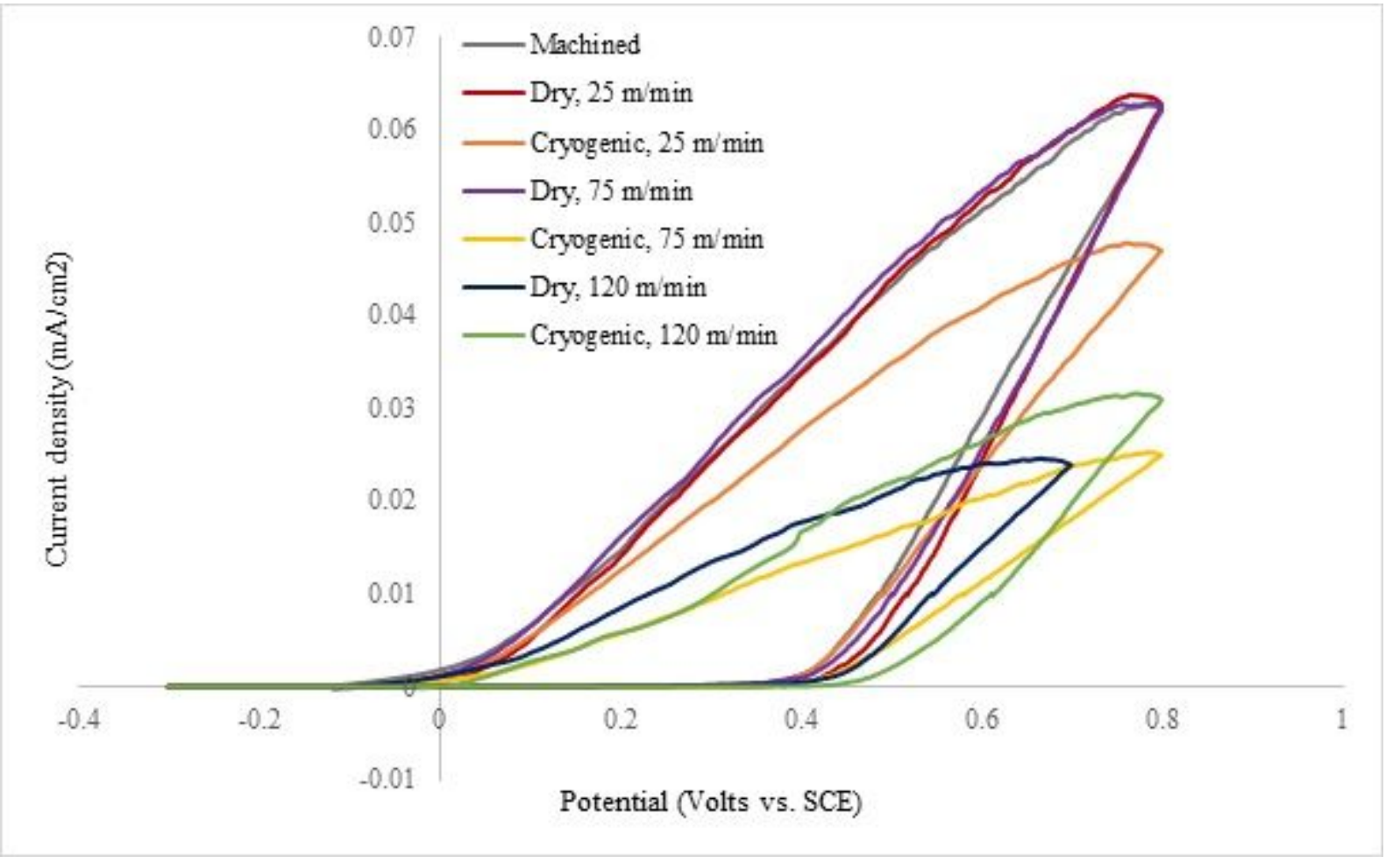

Figure 16

Cyclic potentiodynamic polarization curves of machined and deep rolled samples in synthetic seawate 


\section{Supplementary Files}

This is a list of supplementary files associated with this preprint. Click to download.

- ManuscriptTables.pdf 